\title{
The Mechanism of Swainsonine Causing Early Pregnancy Abnormal Decidualization and Inducing Abortion by Changing Glycosylation Modification
}

\author{
Yi Wang*, Xin Gao, Ming Peng, Yanfei You, Fangyun Shi, Yazhou Guo, Baoyu Zhao\#, Chenchen Wu\# \\ Northwest A \& F University, Animal Medical College, Yangling, China \\ Email: *15303515784@163.com, "zhaobaoyu12005@163.com, "wucen95888@163.com
}

How to cite this paper: Wang, Y., Gao, X., Peng, M., You, Y.F., Shi, F.Y., Guo, Y.Z., Zhao, B.Y. and Wu, C.C. (2018) The Mechanism of Swainsonine Causing Early Pregnancy Abnormal Decidualization and Inducing Abortion by Changing Glycosylation Modification. Advances in Reproductive Sciences, 6, 70-101.

http://dx.doi.org/10.4236/arsci.2018.63007

Received: June 7, 2018

Accepted: August 10, 2018

Published: August 13, 2018

Copyright $\odot 2018$ by authors and Scientific Research Publishing Inc. This work is licensed under the Creative Commons Attribution International License (CC BY 4.0).

http://creativecommons.org/licenses/by/4.0/

\begin{abstract}
Locoweed is a poisonous plant that severely harms the development of grassland and animal husbandry throughout the world. Oxytropis and Astragalus are the Latin names for the poisonous plants commonly known as locoweed. The main toxic substance in these plants is swainsonine. It is a strong inhibitor of lysosomal $\alpha$-mannosidase I and Golgi body $\alpha$-mannosidase II, resulting in the accumulation of oligosaccharides and glycoproteins in lysosomes, interfering with the molecular and cellular recognition of glycans, and causing tissue-cell vacuolar degeneration. Livestock shows a series of clinical and pathological symptoms, mainly for the decline of reproductive performance. The effects in dams are abortion, weak fetus, and fetal malformations. The key step in maintaining pregnancy in dams is early endometrial decidualization, because reproductive hormones, decidual cell apoptosis, endoplasmic reticulum (ER) stress, and other immune factors are negatively affected by swainsonine. This article addresses the modifications that occur through glycan processing and glycosylation resulting in the change of post-translational modification of the protein and the activity of the glycoprotein, and then direct and indirect mechanisms of ER stress, apoptosis, reproductive hormones, immune factors, and cell cycle and other pathways. Our aim is to find new methods of prevention and treatment of swainsonine poisoning in grassland animals.
\end{abstract}

\section{Keywords}

Swainsonine, Glycosylation Modification, Abortion, Decidua, Hormone, Cell Apoptosis, Endoplasmic Reticulum Stress

\footnotetext{
${ }^{*}$ The first author.
} 


\section{Introduction}

Locoweed (Astragalus spp. and Oxytropis spp.) is a perennial flowering plant found frequently in the rangelands of the western United States, Asia, and South America. It is one of the most poisonous weeds and harms grassland and animal husbandry development worldwide [1]. Earlier studies demonstrated that natural or experimental long-term ingestion of SW-containing plants cause serious disorders in reproductive functions of livestock (cattle, sheep, horses, and goat), including failure to conceive, early embryo loss or abortion, which result in great economic losses to the livestock industry [2] [3]. The primary clinical symptom in dams after eating locoweed is miscarriage; however, its complete molecular mechanism is still unclear. The main toxic substance in locoweed, swainsonine, is a water-soluble in dole alkaloid, and as an inhibitor of Golgi mannosidase II (GM II), it can interfere with the synthesis of the glycoprotein N-glycan. Glycosylation is a key factor in the role of proteins [4]. The site of glycosylation is mainly in the endoplasmic reticulum (ER); thus, swainsonine can influence the function of various protein modification functions in the body by inhibiting the activity of glycosylated enzyme, causing the cells to produce a series of abnormal physiological states [5]. The mechanisms of the disorder of decidualization in early pregnancy induced by the swainsonine poisoning are the following: 1) Inhibition of $\alpha$-mannosidase activity triggering the accumulation of oligosaccharides, causing misfolding of nascent peptides by N-glycans. A large number of modified wrong proteins accumulate in the ER and cause severe ER stress. 2) The stress on the ER or directly on the hormone receptor then affects hormone secretion, leading to the failure of the early pregnancy decidualization process. 3) Swainsonine not only induces apoptosis of various factors that cause apoptosis, but also indirectly affects apoptosis through ER stress. We conclude that swainsonine can affect early pregnancy decidualization through the apoptotic pathway, then triggering abortion. This article addresses these three aspects in detail from various angles to uncover the mechanism of swainsonine poisoning that induces early pregnancy decidualization disorder in dams. We aim to provide a new theoretical basis and train of thought for the pathogenesis of swainsonine poisoning.

\section{Locoweed and Swainsonine}

\subsection{The Type and Hazard of Locoweed}

Locoweed, known by the Latin names Astragalus and Oxytropisis a poisonous plant that affects the world's animal husbandry, causing performance degradation and even death [1]. Locoweed poisoning affects cattle, sheep, goats, and horses. Horses are the most sensitive to the effects of locoweed, followed by sheep. Locoweed is one of the poisonous weeds that affect the ecological balance of the natural grassland in northwestern China. Global Astragalus represents 2000 species of plants, of which China has 278 species, 2 subspecies, 35 varieties, and 2 variants, mainly grown in Tibet, Central Asia, and the north of China. Global Oxytropis represents approximately 350 species, mainly distributed in 
temperate and sub-arctic countries in the region, and in the northwest regions of China, such as Gansu, Qinghai, Ningxia, Tibet, and Shaanxi [6]. Cause livestock poisoning Oxytropis main plants are: Oxytropis glacialis Benth. ex Bunge, Oxytropis ochrocephala Bunge, Oxytropis kansuensis Bunge, Oxytropis deflexa (Pall) DC and so on. Table 1 shows poisonous plants Oxytropis poison livestock and economic losses. Grasshoppers have a tremendous toll on natural grasslands. Only sericulture Oxytropis and pilose Astragalus cause livestock poisoning in the United States, resulting in an annual economic loss of more than \$234 million. China's Tibet every year due to livestock locoweed poisoning caused by a billion dollars in economic losses [7]. The average content of swainsonine in locoweed is the highest, reaching $0.148 \%$, with the lowest being $0.044 \%$ [ 8 ].

Locoweed reduces other vegetation due to its own good growth characteristics (drought resistance, cold resistance, resistance to poverty, resistance to insect pests, early greening, late withered). It cause the soil nutrients decreased, productive forces, utilization rate down, grassland degradation faster, lawn effective stocking becoming low, changing herd structure and other issues. Due to the serious degeneration of naturally available herbage and the spread of locoweed, livestock have to eat locoweed and then caused poisoning phenomenon. Therefore, pastoralists carried out a series of locoweed control work. However, the unreasonable prevention and control of locoweed, for example unreasonable using the herbicide can also lead to deterioration of the grassland, even accumulation in the food chain and endanger human health. Tibet has used Xinjiang fine wool sheep, cigai sheep and caucasian sheep to improve native breed of sheep since 1977. Although the improved sheep improve production performance, their recognition of poisonous grass are greatly reducing and are more poisoning than local varieties. Coupled with abortion and other factors after poisoning, the action hinder the improvement of breeding.

\subsection{The Poisonous Substance in Locoweed: The Discovery of Swainsonine}

The Leguminosae Oxytropis spp plant contains indoxylidine alkaloids toxic

Table 1. Poisonous and economic loss of oxytropis plants to animals.

\begin{tabular}{cc}
\hline Direct damage (impact in animals) & Indirect losses (management cost) \\
Dead & Fence establishment and maintenance \\
Malfortion & Increased feed requirements \\
Abspecken & Increased medical treatments \\
Lengthened calving interval & Altered grazing programs \\
Decreased fertility & Decreased forage availability \\
Decreased immune response & Decreased land values \\
Dccrcased function & Opportunity costs \\
Loss of breeding stock & Lost time to management \\
\end{tabular}


components that can cause chronic neurological dysfunction in animals, manifested as mania; thus, the plant was referred to as locoweed. Earlier studies suggested that the reason for livestock poisoning caused by Oxytropis is excessive selenium. However, the study by Zhang Shengmin et al. found that the symptoms and lesions of Gansu Oxytropis poisoning and selenium poisoning are not exactly the same in Qinghai area livestock through incidence, poisoning symptoms, and pathological changes. They first put forward that Oxytropis poisoning in China is not caused by selenium. Cauch (1929) isolated a kind of locoweed toxin from the Lambertian Oxytropis that can cause cat locoweed disease. He described the toxin as a stable nitrogen-containing compound with multiple hydroxyl groups. It can dissolve in water but not in chloroform, ether, and hydrocarbon solvents. However, due to the conditions at that time, they failed to identify its structure. Colegate (1979) used $\alpha$-mannosidase as a tool to isolate a pure toxin for the first time from the gray bitter horse beans and identified it as indolizidine alkaloids-swainonine [9]. Molaneux (1982) took swainonine isolated from Colegate's study as a standard to isolate swainsonine and swainsonine $\mathrm{N}$-oxide from Astragalus membranaceus and silkworm Oxytropis and believed that swainsonine is the major toxic component of the American locoweed. James et al. [10] pointed out that swainonine is the only toxin in plants that can cause the symptoms of locoweed poisoning in the academic conference of swainsonine and related glycosidase inhibitors. The molecular formula of swainonine is $\mathrm{C}_{8} \mathrm{H}_{15} \mathrm{NO}_{3}$. The relative molecular mass is 173 . The three hydroxyl groups on its molecular structure may be inseparable from its strong specific inhibition [11] (Figure 1).

The molecular formula of swainonine is $\mathrm{C}_{8} \mathrm{H}_{15} \mathrm{NO}_{3}$. There are three hydroxyl groups on the molecular structure.

\subsection{Effects of Swainsonine on the Reproductive Performance of Livestock}

The typical symptom of swainsonine poisoning is to affect the reproductive performance of livestock. It not only has negative effects on the reproductive

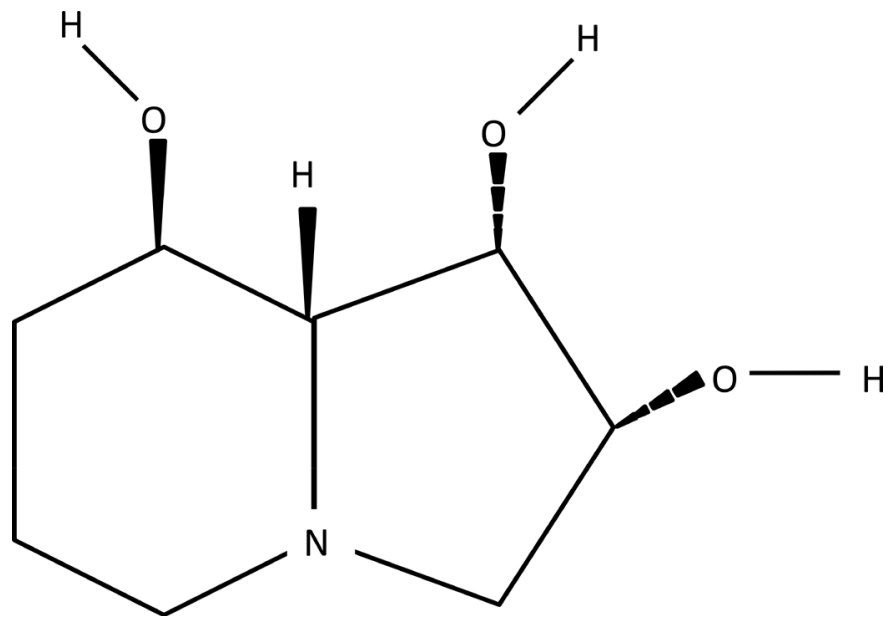

Figure 1. The structure of swainsonine [11]. 
performance of adult males and females, but also causes toxic effects on young animals. Poisoned dams not only frequently miscarry, but also can give birth to a weak fetus, a stillborn fetus, a deformed fetus, or a rotten fetus. Gansu Oxytropis and black calyx Oxytropis poison female deer, making it difficult for them to become pregnant. Pregnant mares may miscarry. Oxytropis sericea bean poisoning in the goat causes placenta dysplasia, inhibited uterine vascular development, and fetal malformations, but no poisonous addiction [2]. Oxytropis glabra poisoning in pregnant sheep causes uterine hydronephrosis, abortion, and lambs with thin, weak legs. Oxytropis kansuensis poisoning in pregnant goats causes frequent urination, vaginal secretion of white mucus, abortion, stillbirth, rotten fetus, or a weak kid that will eventually die. Oxytropis glacialis, which is found in Tibet, leads to stillbirth and miscarriage in pregnant dams, or abdominal rupture in fetuses [3]. Rabbits, mice, and other animals have similar symptoms. Females in estrus show abnormal behavior, prolonged estrus cycles, and cannot conceive. Swainsonine affects estrogen and progesterone secretion and its receptors as well as vacuolar degeneration of ovarian luteal cells and placental trophoblast cells.

Male animals affected by swainsonine show testicular damage, and testicular and epididymal weight loss. Decreased testosterone induces loss of libido. Testicular spermatogenic cells and epididymal epithelial cytoplasm show extensive vacuolar degeneration. The nucleoli of spermatogenic cells are broken and present vacuolar degeneration. Cytoplasmic granules show vacuolization. Epididymal tubular cell nuclei show degeneration. Mitochondria show swelling and vacuolization. Sperm cells show deformity. JB Richards et al. conducted a 21-day locoweed feeding experiment on male lambs, finding that luteinizing hormone levels in serum were basically stable but testosterone levels decreased after injection of gonadotropin-releasing hormone on the day 22. On day 50, lamb serum luteinizing hormone began to decrease, and the testosterone area under the curve (AUC) was numerically lower in locoweed-fed rams than in control animals [12].

Visible swainsonine not only affects the function of germ cells, but also have an impact on the relevant reproductive hormones.

The molecular weight of SW is smaller. It can be metabolized through breast milk, leading to young animals poisoning by sucking breast milk. Oxytropis glabra poisoning ewes, lambs Because of its breast feed their symptoms occur only mild symptoms [13]. In summary, swainsonine poisoning has a significant negative effect on the reproductive performance of livestock. Livestock fecundity decrease, leading to ranch economy serious loss.

\section{The Mechanism of Action of Swainsonine Toxicity}

A large dose of swainsonine has a strong cytotoxicity to the body cells, but a small dose of swainsonine also has the ability to regulate the immune system, protect the cells, inhibit bacteria, and act as an antiviral. Swainsonine can also inhibit tumor metastasis, and play a role in cell diffusion and cell apoptosis. 
Swainsonine is the major toxic component of Astragalus and Oxytropis poisonous plants. Because of its cationic spatial structure similar to the mannose cationic semi-chair-like structure formed during the hydrolysis of mannoside and its very high affinity for $\alpha$-mannosidase, it inhibits the activities of lysosomal $\alpha$-mannosidase I (LAM I), GM II, and cytoplasmic $\alpha$-mannosidase. In particular, the hydrolase activity is lost. Swainsonine changes the cell surface oligosaccharide structure and metabolism (Figure 2). Then, it directly influences various cells and their physiological functions, causing a large accumulation of mixed asparagine oligosaccharides. Cell vacuolar degeneration eventually occurs (LAM inhibition). N-glycan glycosylation of intracellular protein synthesis, processing, transport, and other processes change. LAM inhibition causes abnormal reproductive function, endocrine disorders, and immune function disorders, and other phenomena (GM II inhibition) [14].

Because of SW cationic spatial structure similar to the mannose catalyzed semi-chair-like structure formed during the hydrolysis of mannoside and its very high affinity for $\alpha$-mannosidase. Causing cell degeneration occurs.

\subsection{Glycosylation and Its Associated Glycosinase}

Studies have shown that, Golgi marker enzymes are glycosyltransferases, wherein a variety of proteins involved in cell proliferation, differentiation, migration, apoptosis and tumor metastasis and transmitting signals [14]. Although the transfer of initial sugar(s) to glycoproteins or glycolipids occurs in the ER or on the ER membrane, the subsequent addition of the many different sugars that make up a mature glycan is accomplished in the Golgi, the main role of the sugar chain structure mediates cell recognition and molecular recognition [16]. There are two common glycosylation modifications: O-glycosylation and N-glycosylation.

$\mathrm{O}$-connecting $\mathrm{N}$-acetylglucosamine modification (O-GlcNAc) is a protein post-translational modification that is ubiquitous in eukaryotic cells [17]. Only OGT and OGA regulate O-GlcNAc modification in the biological body. O-G1cNAc
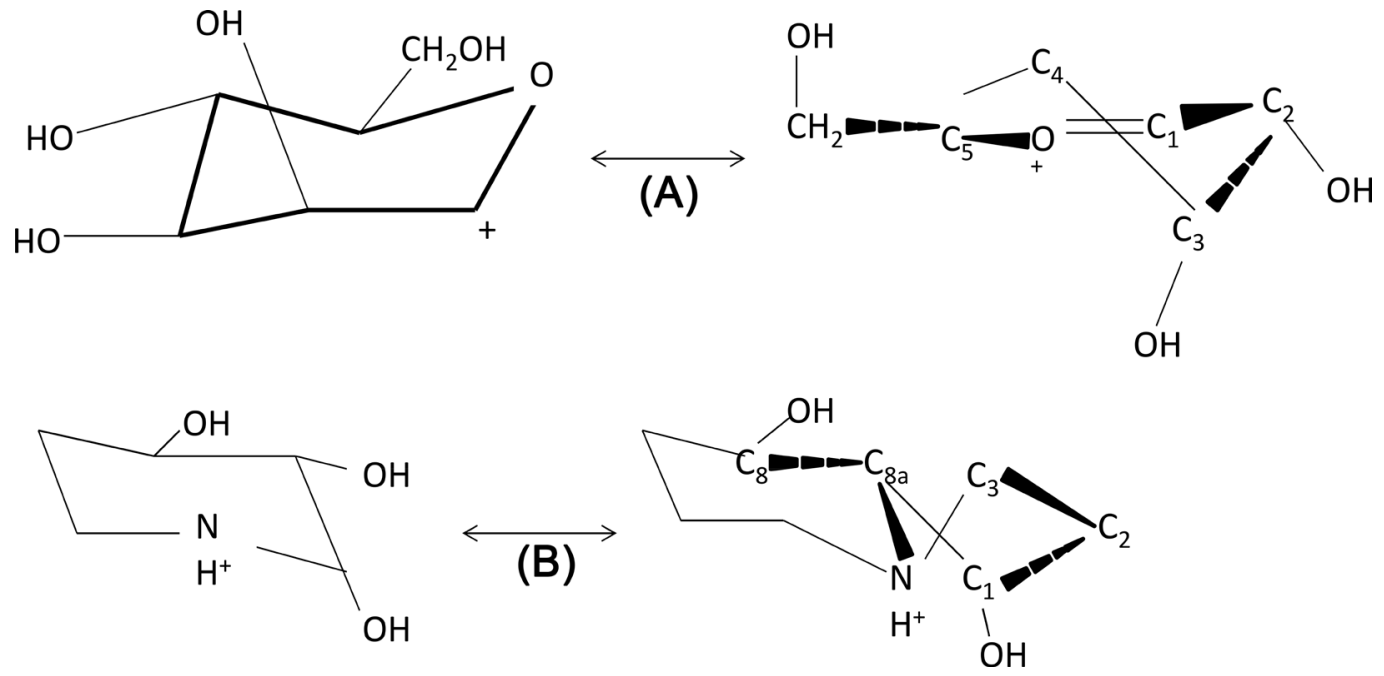

Figure 2. Compare of mannose cation (A) and SW cation (B) Three-dimensional structure [15]. 
transferase OGT (O-G1cNAc transferases) belongs to the GT41 family of polysaccharide transferases. The human OGT gene is located on the X Chromosome [18]. The role of OGT is to link acetylglucosamine to the serine or threonine hydroxyl of the target protein. The role of OGA is to remove the modification (Figure 3). At present, this modification is found in more than 3000 kinds of proteins from C. elegans to higher mammals (i.e., humans), such as tumor suppressor, various enzymes, and modified proteins. It can be said that the vast majority of cells in the body are affected by OGT participation [19]. It occurs in major diseases like cancer, and the abnormality can be detected depending on O-glycosylation modification levels [20]. The early development and growth of embryonic stem cells cannot be separated from OGT. Higher animal knockout OGT can cause cell loss or even cell death. The impact on lower animals is mainly reflected in the metabolic aspects [21].

The role of OGT is to link acetylglucosamine to the serine or threonine hydroxyl of the target protein. The role of OGA is to remove the modification.

$\mathrm{N}$-linked sugar chains extend from the ER to the Golgi apparatus. Polysaccharides embedded in the ER are a starting point for $\mathrm{N}$-polysaccharification. $\mathrm{N}$-polysaccharification contains 14 monosaccharides. They are respectively three glucose, nine mannose, and two $\mathrm{N}$-acetylglucosamine. In the ER and the Golgi apparatus, there are specific glycosidases and glycosyltransferases to catalyze them [23]. Glycosylation of N-glycans is also an essential post-translational modification of protein synthesis, and has a close relation with the biological behavior of malignant tumors [24]. GM II is a key enzyme in the N-glycosylation pathway. Swainsonine can inhibit LAM I and GM II, thus inhibiting tumor cell growth and proliferation metastasis [25].

In humans, livestock, birds, insects, microorganisms, and plants, a variety of organelles distribute $\alpha$-mannosidase, such as the ER, the Golgi apparatus, lysosomes, and cytoplasm [26]. $\alpha$-mannosidase is primarily associated with protein glycosylation modification and glycoprotein hydrolysis modification. $\alpha$-mannosidase is divided into three categories. It is currently determined that the second category is swainsonine inhibited. The class II $\alpha$-mannosidase substrate is Man5GlcNAc2 and G1cNA-Man5GlcNAc2, partially acting on Man3GlcNAc2, but having no catalytic effect on Man3GlcNAc. As the essential enzyme in protein N-glycan glycosylation modification, GM II plays a role in the cutting of $\mathrm{N}$-sugar chain mannose residues, converting glycans from high mannose to complex structures. Because it contains the familial sugar hydrolytic enzyme

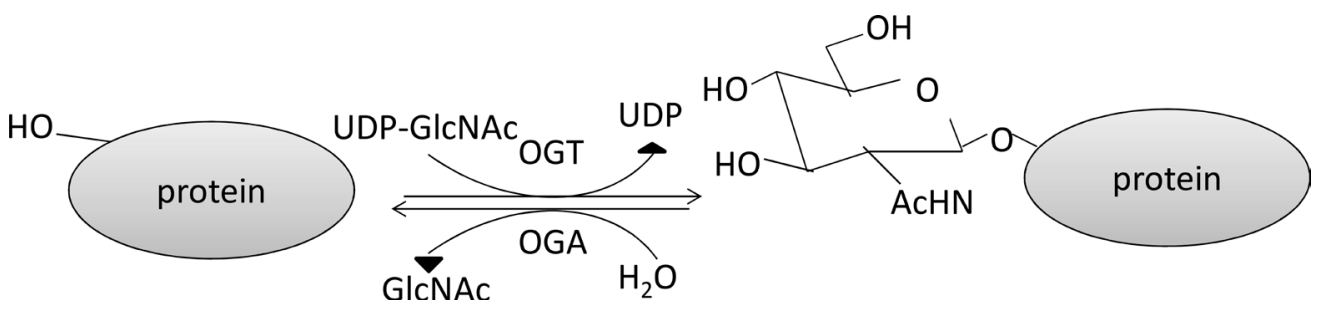

Figure 3. OGT and OGA regulate O-GlcNAc to achieve modification [22]. 
conservative sequence, it is possible to specifically cut the $\alpha-1,3$ and $\alpha-1,6$ linked mannose residues on GlcNA2Man5GlcNAc. The structure of the glycosyl moiety is formed by the cleaved sequence and serves as a basic precursor for further incorporation of $\mathrm{N}$-acetylglucosamine units [27].

The $\mathrm{N}$-acetylglucosamine transferase exists in the Golgi body. Its primary function is to develop it into a multi-branched structure based on the core pentasaccharide. GlcNAc(Gn) glycans in the donor substrate UDP-N-acetylphthalopyranoside (UDP-G1cNAc) are transferred to two mannose saccharides at the core of the $\mathrm{N}$-glycan pentasaccharide to participate in the synthesis of asparagine-linked glycans (N-glycans) or serine/threonine-linked glycans (O-glycans) (Figure 4). It is extremely important in living organisms. There are currently six confirmed $\mathrm{N}$-acetylglucosamine transferases. Among them are $\mathrm{N}$-acetylglucosaminyltransferase III and V (GnTIII,V), which are two important N-sugar chain synthases. GnT III can transfer G1cNAc in UDP-G1cNAc to $\beta$-mannose in the N-glycan core in a $\beta 1,4$-linked manner, catalyticing generation of bisected G1cNAc. Once the structure of the bisector is created, other glycosyltransferases, especially GnTV, can no longer modify the glycosylation. Whereas, GnTV catalyzes the transfer of G1cNAc in UDP-G1cNAc to the G1cNAc $\beta 1$, 2Mana1, 6 Man $\beta 1$, and 4G1cNAca linked mannose residues in a $\beta 1,6$-linked manner. In other words, high expression of GnT III has an inhibitory effect on the N-sugar chain $\beta 1,6$ branch, whereas GnTV is advantageous to the $\mathrm{N}$-sugar chain $\beta 1,6$ branch [28] (Figure 5).

The oligosaccharide precursor during the maturation of $\mathrm{N}$-glycans is $\mathrm{GLc}_{3} \mathrm{Man}_{9} \mathrm{GlcNAc}_{2}$. The distal three glucosyl groups are first specifically excised by glucosyltransferase, producing $\mathrm{Man}_{9} \mathrm{GlcNAc}_{2}$ and then hydrolyzed by class I a mannosidase to remove four mannose formations. $\mathrm{Man}_{5} \mathrm{GLCNAc}_{2} \cdot \mathrm{Man}_{5} \mathrm{GLCNAc}_{2}$ is modified by $\mathrm{N}$-acetylglucosamine transferase $\mathrm{I}$, which is linked to an $\mathrm{N}$-acetylglucose to form $\mathrm{GlcMan}_{5} \mathrm{GlcNAc}_{2}$, which is transported to the Golgi apparatus and cut by type IIa-mannosidase to remove two nectars. The sugar

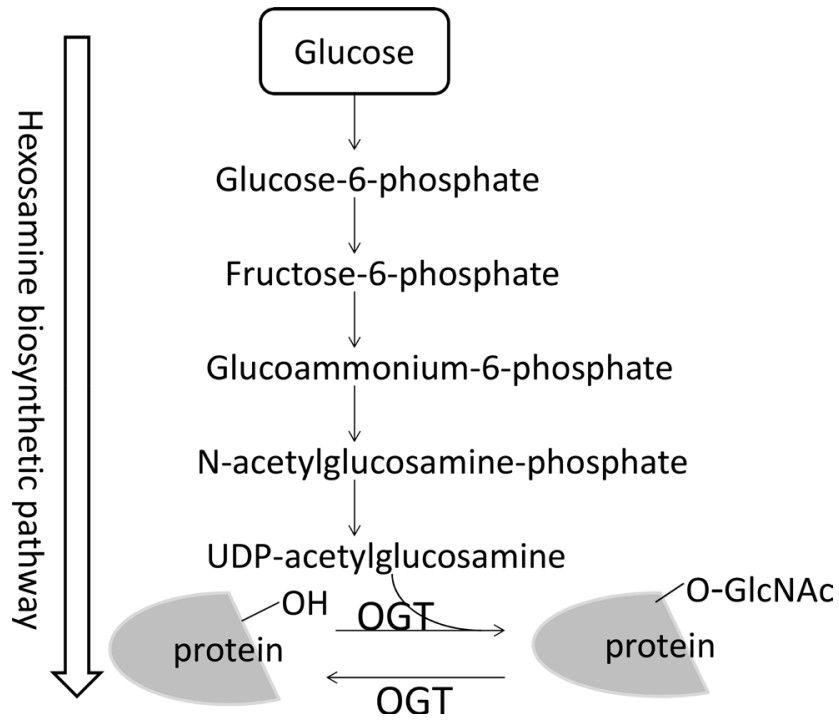

Figure 4. O-Glycan processing [28]. 
N-glycosylation:Endocrine proteins/Amino acid residue aspartic acid membrane binding protein + Oligosaccharides

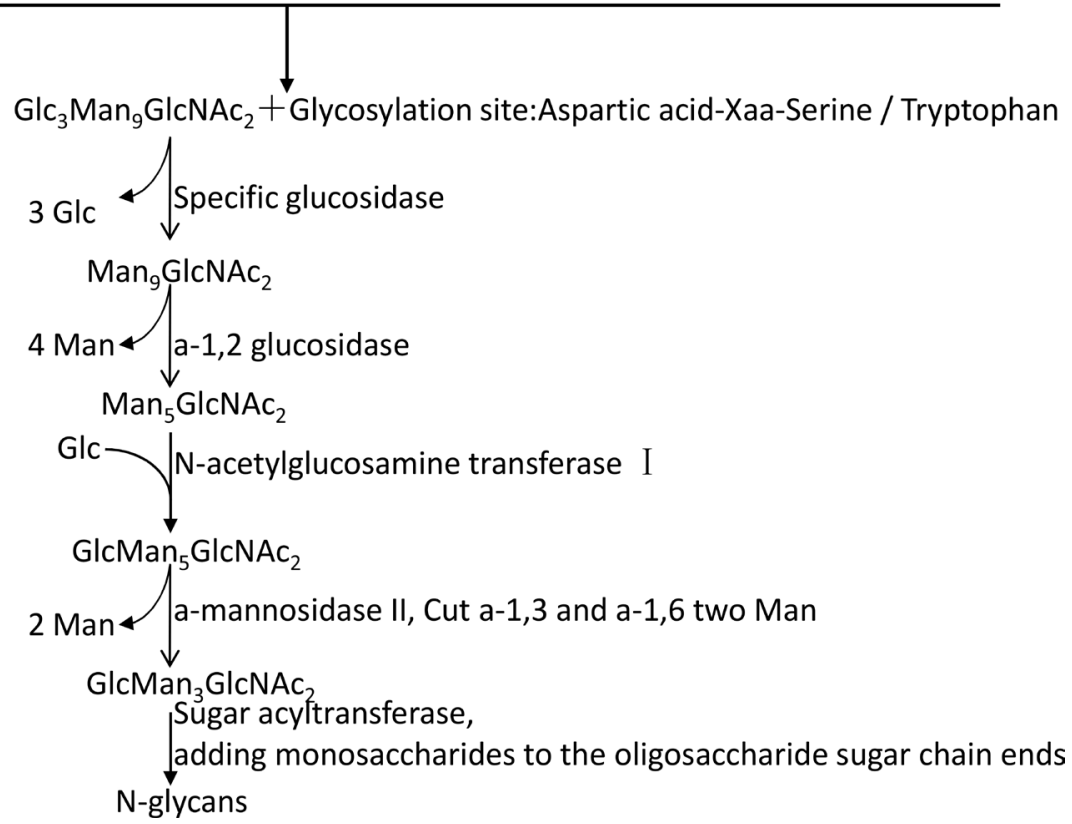

Figure 5. N-Glycan processing [28].

forms $\mathrm{GLcMan}_{3} \mathrm{GlcNAc}_{2}$, which is transported by the glycosyltransferase to the terminal of the oligosaccharide branch sugar chain. The $\mathrm{N}$-glycan is processed and the processed N-glycan is transported to specific tissues and organs to perform physiological functions.

The reducing end of the glycosyl or sugar chain is linked to the oxygen atom (O) of the hydroxyl group of Ser, Thr, or hydroxylysine residues in the protein peptide chain as an O-linked sugar group or sugar chain. Mucins are the major type of O-glycosylated glycoprotein and are enriched with highly O-glycosylated Ser/Thr/Pro tandem repeat regions.

\subsection{The Effect of Swainsonine on Glycosylation Modification}

Swainsonine Inhibit Golgi $\alpha$-Mannosidase II (GMII) and then leads to N-glycan glycosylation abnormalities and the expression of specific membrane glycoproteins. Therefore, the structure of oligosaccharide in cell membrane is changed [28]. Simultaneously, the $\alpha$-mannosidase hydrolysis activity is suppressed, making a large number of oligosaccharides accumulate in the cell, causing vacuolar degeneration. It also hinder the endoplasmic reticulum protein misfolding, mutation and other degradation of glycoproteins.

Most cell adhesion molecules are in the form of $\mathrm{N}$-glycan glycosylated. Swainsonine acts as an N-glycan glycosylation inhibitor to block the N-glycan glycosylation pathway and then it causes lesions. Swainsonine, an inhibitor of $\mathrm{N}$-glycan processing, reduces the $\mathrm{N}$-glycan branch of cellular glycoproteins, including $\mathrm{N}$-glycans linked to the $\mathrm{Na}-\mathrm{K}$ ATPase, and the normal branch of $\mathrm{N}$-glycans decreases Cell pump permeability is significantly reduced, resulting in increased cell-cell tightness and stability [29]. Swainsonine can make the closely 
connected components not glycosylate and increase the stability of the adhesion connexin (E-cadherin) to the detergent extraction. These properties may be used to promote wound healing both in vitro and in vivo, and reduce tumor invasiveness. Swainsonine inhibits the expression of $\beta 1,6 \mathrm{~N}$-sugar chain on the surface of osteosarcoma stem cells [30]. Swainsonine and other inhibitors of $\mathrm{N}$-glycosylation impede prion infection in a strain- and cell-specific manner, Even though the mechanism by which swa and other glycosylation inhibitors exert their effects remains unclear, their use has significantly enhanced the discriminatory power of the cell panel assay [31]. Swainsonine poisoning can also cause a variety of intracellular (liver most obvious) sliding surface ER changes, rough ER threshing and swelling, or even rupture [32]. Immunoglobulin $M$ (IgM) has five N-glycosylation sites; researchers have speculated that inhibition of elongation of $\mathrm{N}$-glycans by treatment with swainsonine enhances the degradation of immunoglobulins by some protease [33]. It has been found that by SW treatment, the $\mathrm{N}$-glycosylation of the heavy chain of IgM can be reduced and the heavy chain of IgM can be shortened, which may reduce the anti-IgM induced growth inhibition, and reduction in anti-IgM-induced growth inhibition due to altered $\mathrm{N}$-glycosylation may enhance CD40-CD40L-mediated cell survival through TRAF2 which interacts with both IgM and CD40 in HBL-2cell, affect the prognosis of DLBCL patients, but also have an impact on apoptosis [34] (Figure 6). Cell adhesion and invasion to galectin-1 appeared to be regulated by cell surface sialylation and $\mathrm{N}$-glycosylation, whereas the $\mathrm{N}$-glycosylation inhibitor swainsonine treatment causes cell-galectin-1 adhesion enhancement [35]. In summary, swainsonine as GM II inhibitor, caused most of the complex glycoproteins to be replaced by hybrid types; but, a smaller amount of the asialo hybrid was also produced [36]. Swainsonine can also inhibit LAM I, causing the accumulation of oligosaccharides. The inhibition of LAM I and GM II will affect the $\mathrm{N}$-sugar chain synthesis and modification processing, resulting in abnormal

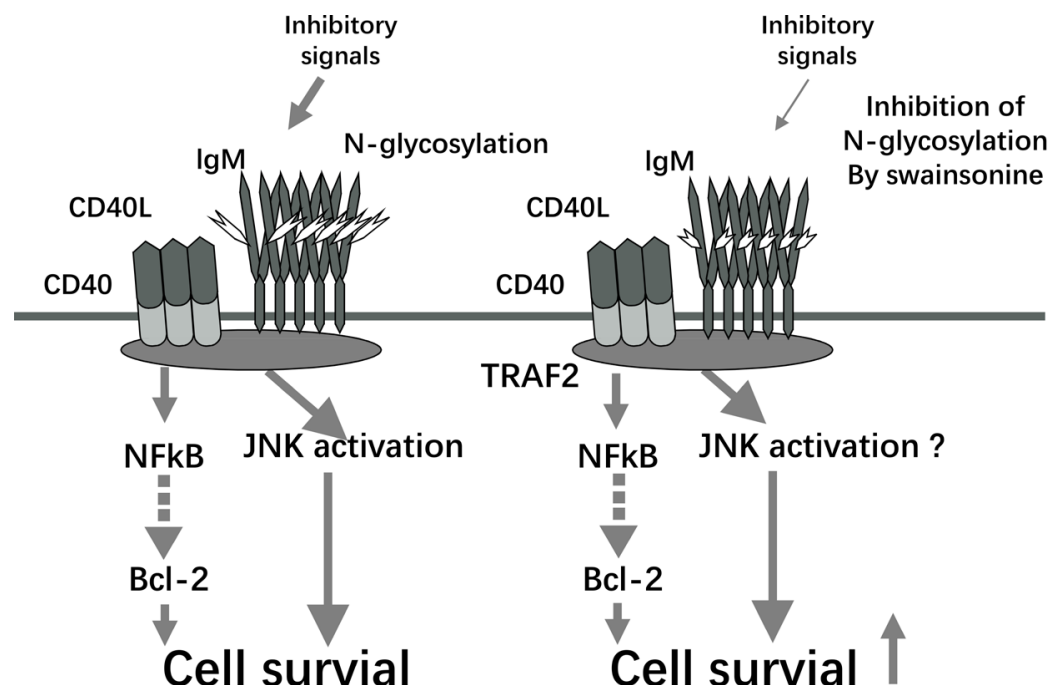

Figure 6. The regulation effect of N-glycans on immunoglobulin $\mathrm{M}$ in the CD40-CD40L system in HBL-2 cells [34]. 
glycoprotein and the accumulation of oligosaccharides in lysosomes. Then, it causes cell vacuolar degeneration, tissue and organ damage, and even dysfunction.

The CD40-CD40L system is known to rescue germinal center B cells from apoptosis through up-regulation of bcl-2 family proteins, such as bcl-XL, or regulate germinal center $B$ cell differentiation. Others have reported that the CD40-CD40L system protects B lymphoma cells from apoptotic signals through up-regulation of bcl-2 oncoprotein. Recent studies showed that human B lymphoma cells survive through the autocrine action of CD40L, which results in autonomous cell growth. IgM has five $\mathrm{N}$-glycosylation sites.

\section{Effect of Swainsonine on the Decidualization of Early Pregnancy in Domestic Animals}

\subsection{Early Pregnancy Decidualization}

Uterine decidualization is a temporary process of heterogeneous tissue composed of multiple cells during pregnancy. Decidualization protects the fetus from maternal rejection and plays an important role in the maintenance of early pregnancy. In most mammals, stromal cells surrounding the blastocyst begin to proliferate and differentiate immediately on adhesion of the blastula and uterine cavity epithelium. This process causes a change in the morphology and function of the stroma (decidualization), and the volume and weight of the site of implantation of the embryo is rapidly increased so that the blastocyst can be completely embedded into the sub-matrix [37].

Early in the primate and rodent pregnancy, successful implantation is the result of the ability of the implanted blastocyst to interact with the uterus of the recipient, where free blastocysts must adhere to the uterine cavity epithelium and invade the uterine stroma. Then, the stromal cells, beginning interstitial loosening to ensure the smooth implantation of embryos [37]. The period in which the endometrial receptivity to embryo implantation in the uterus is most marked is called the "window" period. Research shows that this period is under the control of progesterone (P4) and estradiol (E2) regulation [38]. Endometrial stromal cells at the embryo implantation were decidual cells transformed to support the survival and implantation of embryos and the early blastocyst [39]. Mice underwent embryo implantation on day 4 of pregnancy, and embryos surrounding stromal cells began to proliferate and differentiate into multinucleated cells and then decidual cells. Decidual cells undergo characteristic morphological changes: changes in epithelial cells occur, multinucleated nuclei form, prominent nucleoli form, the nuclear membrane recesses, a large number of glycogen form in cytoplasm, forming lipid droplets, and then mitochondria and ER, eventually forming large rounded cells, marking the success of decidualization [40]. Decidualization has several roles: 1) Maternal decidua are a barrier, limiting trophoblast invasion only to the inside of the myometrium, and not allowing intrusive destruction of muscle tissue or even rupture of the uterus, so the fetus 
can reduce the damage caused by the invasion of the womb; 2) functions as an immune barrier to prevent rejection of the fetus by the mother; 3 ) the spiral arteries on the surface of the uterus change significantly from high resistance and low flow to large vessels with low resistance and high flow, which form the basis for the material exchange between uterus and placenta; 4) may be related to the formation of the placenta, and provide the embryos with growth factors and cytokines before placenta formation; and 5) decidual stromal cells in the process of apoptosis by spontaneous degradation can provide enough space to form the placenta [41]. Inappropriate decidualization may lead to uterine dysfunction, and ultimately lead to pregnancy failure [42] (Figure 7).

A potential model for stromal cell proliferation, differentiation, and terminal differentiation for polyploidization during the progression of uterine decidualization.

\subsection{Decidualization-Related Hormones}

Uterine decidualization occurs by hormones, cytokines, transcription factors, and other factors [43]. Wherein the hormone is particularly important in the process of decidua, there have been many studies showing that the endometrium decidualization is regulated by a variety of hormones, such as estrogen, progestin, prostaglandin, relaxin, gonadotropin, luteinizing hormone, follicle-stimulating hormone, human chorionic gonadotropin, and adrenocorticotropic hormone [44]. But, the primary regulatory hormones are estrogen and progesterone. Hormone secretion during mouse embryo implantation is divided into three phases. In the first phase, early estrus, E2 peaks before ovulation, when almost no P4 secretion occurs. In the second phase, within 2 days of mating, E2 and P4 secretion is very low. In the next phase, the third and fourth days of pregnancy until the formation of the corpus luteum, P4 secretion increases rapidly to maintain a stable high level of secretion to maintain pregnancy. On day 4 of pregnancy to the morning of day 5, there is a small peak in E2, called luteal phase E2, which is the "window" period. Uterine receptivity has started, and
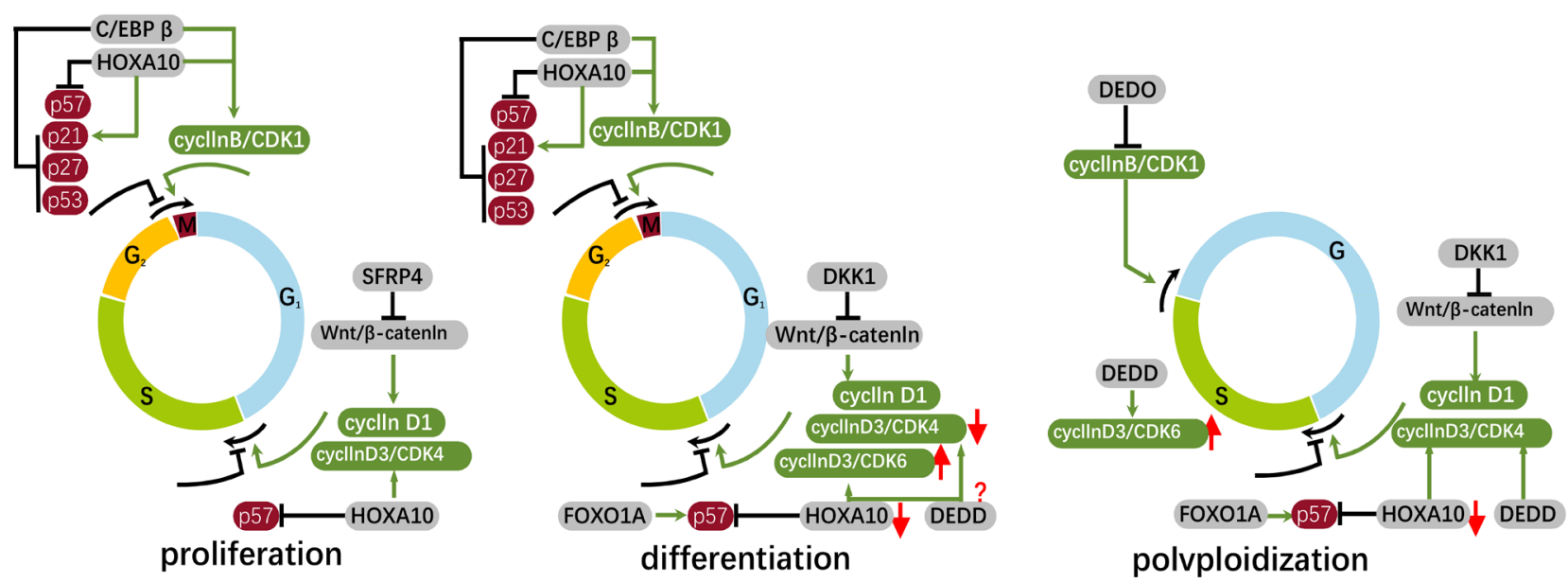

Figure 7. Cell cycle regulation during proliferation, differentiation and multinucleation in ESCs decidualization [42]. 
embryo implantation occurs. E2 is necessary for embryo implantation, and the dose required is small and sensitive [45] (Figure 8). That is, endometrial epithelial cells and stromal cells begin to proliferate under the action of estrogen, and as progesterone increases, endometrial stromal cells are transformed into the secretory phase and undergo decidualization [46]. Androgen, including testosterone, dihydrotestosterone, and other substances with androgenic activity on decidualization, also have a certain impact. High concentrations of dehydroepiandrosterone (DHEA) can inhibit the proliferation of endometrial stromal cells and reduce the decay of prolactin associated with membrane protein (dPRP) mRNA expression [47]. Foreign studies have shown that high concentration (pharmacological concentration) of dehydroepiandrosterone (DHEA) inhibit intracellular glucose-6-phosphate dehydrogenase activity, thereby inhibiting mouse and human endometrium in vitro and in vivo decidualization is not conducive to embryo implantation [48]. During decidualization, progesterone significantly inhibits androgen receptor (AR) protein expression, whereas estrogen dramatically elevated AR abundance in the stroma of ovariectomized mouse uteri; therefore, the number of androgen receptors in decidual tissue is lower than in normal stromal cells [49]. A recent study found that ovarian stimulation using human chorionic gonadotropin (hCG) induces an imbalance in steroid hormone secretion, which causes a failure of the development of uterine receptivity and subsequent implantation and decidualization by altering the expression of steroid receptors and their downstream signaling associated with embryo implantation [50].

Pre-implantation hormone secretion patterns are divided into three stages: 1) Pre-ovulatory estrogen peaks (preoestrus estrogens) exist in the early estrus of

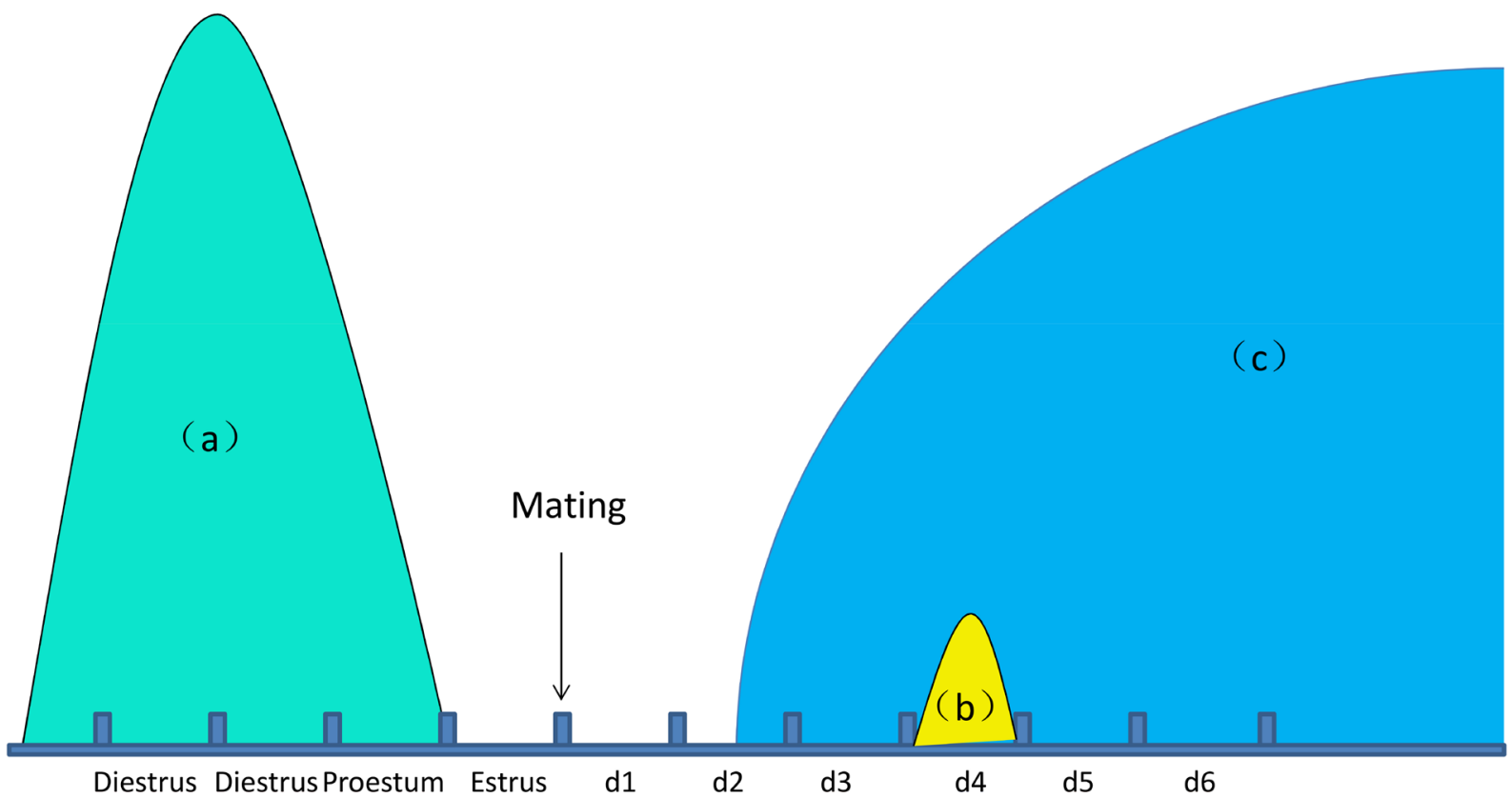

Figure 8. Schematic diagram of hormone secretion during mouse implantation [51]. (a) preovulatory estrogen; (b) luteal phase estrogen; (c) progesterone. 
mice, and progesterone is almost absent during this period; 2) Two days after ovulation (which is also the time when mating occurs in mice), both estrogen and progesterone levels are very low; 3 ) After this period, progesterone levels are rapidly increasing with the formation of the corpus luteum. Increased (days 3 to 4), while estrogen secretion also showed a small peak on the fourth day of pregnancy, lutein-phase estrogen (luteal-phaseestrogen, day 4).

In primates, the decrease of progesterone during menstruation is the key factor that causes necrosis, disintegration, and hemorrhage of endometrial decidua. The physiological (P4) effects of progesterone progestins on endometrial stromal cells is mediated by interaction of the hormone with specific intracellular progesterone receptors (PGR) that are expressed from a single gene as two protein isoforms. PGR has two subtypes, PGR- $\alpha$ and PGR- $\beta$, and although PGR-a is 164 -amino acids shorter at its $\mathrm{N}$-terminus than PGR- $\beta$, its molecular weight is smaller, and it plays a major role in the uterus [52]. If the two subtypes lack both receptors, more female animals showed abnormalities and reproductive defects, including defects of deciduas [53]. The decrease of progesterone receptor is one of the causes of spontaneous abortion. The gene and protein expression of progesterone receptor in spontaneous abortion is lower than normal [54]. The current abortion drug, mifepristone, can inhibit decidual progesterone receptor binding and the decidual tissue degeneration, while inducing decidual and villus apoptosis and then terminating the pregnancy [55]. During rodent and human decidualization, in general while both PgR subtypes were present in glands and stroma in the proliferative phase, and both subtypes were dramatically reduced in the glands during the secretory phase, PgRA remained as the predominant type in the stroma during the secretory phase and early pregnancy. The profound effects of progesterone on endometrium during the secretory phase and early pregnancy appear to be mediated primarily by PgRA in the stroma [56]. Luman-recruiting factor (LRF) protein in the process of decidualization showed high levels of expression in the mouse uterine primary decidual area and secondary decidual area. LRF protein was significantly positive staining [57]. When the ER-stress occurs, similar to adjust the membrane hydrolysis mechanism of ATF6 to split Luman protein, then Luman protein's N-terminal protein enter into the cell and activate the downstream target genes (Figure 9) [58]. The expression of the LRF protein in the stromal can be increased by $\mathrm{P} 4$ which is helpful to decidua, to a certain extent, it can be inhibited by E2 which is not conducive to decidua. Therefore, the large secretion of P4 plays a role in maintaining the pregnancy [59].

Working model for the cellular function of Luman recruitment into the LRF nuclear bodies. Luman is a type II transmembrane protein which is normally bound to the ER. During cellular stress responses such as the UPR, Luman undergoes regulated intramembrane proteolysis, and subsequently the $\mathrm{N}$-terminal region of Luman translocates to the nucleus. In the absence of interaction with LRF, nuclear Luman binds to the cofactor HCF-1 and forms a transcription 


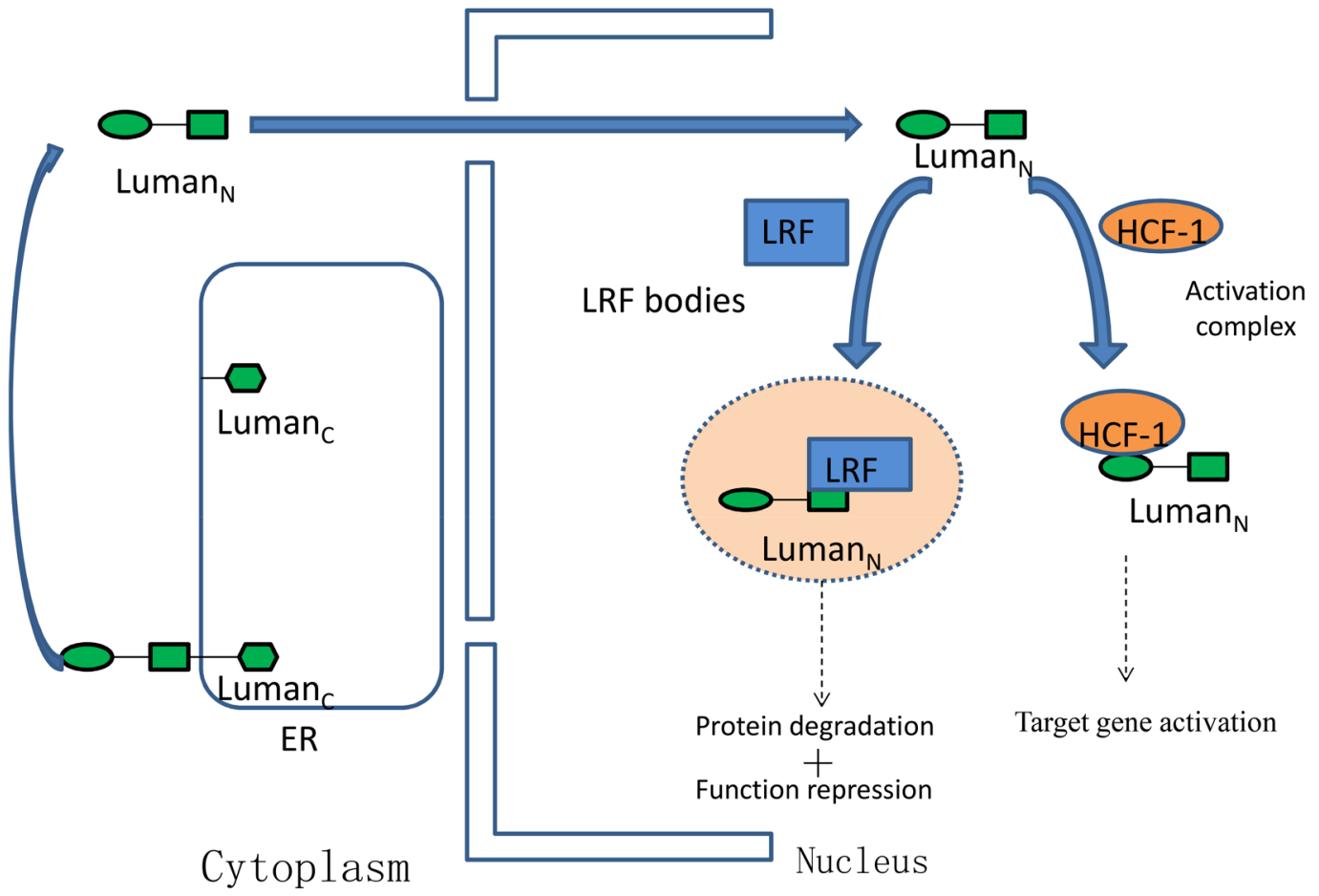

Figure 9. Luman and LRF intracellular model diagram [60].

activation complex, leading to the activation of downstream target genes, such as the UPR-related Herp and EDEM. At a point of the UPR where the cellular environment changes and the level of LRF in the nucleus rises to a threshold, Luman may be recruited in the LRF bodies and sequestered from HCF-1, which results in accelerated proteasomal degradation and repression of the transactivation function of Luman.

\subsection{Swainsonine and Decidualization and the Relation between Hormones}

The mammalian uterus is the target organ for changes in morphology and function of the organization by hypothalamic-pituitary-gonadal axis precision regulation of sex hormones. Hormones are the key regulators of physiological and pathological functions, given the high levels of early pregnancy estrogen to suppress the endometrial decidualization process. E2 can induce uterine epithelial apoptosis in rodent uterus; $\mathrm{P} 4$ has an opposite effect; and the ER stress pathway can induce the expression of P4. Meanwhile, it is confirmed that ER stress GRP78 is regulated by E2 in the rat uterus [61]. Decreased progesterone can lead to disintegration of decidual tissue, maintain a certain amount of progesterone can extend the life of the decidual tissue [62]. Although studies have shown that estrogen receptor knockout on animal decidualization is not obvious, estrogen can regulate progesterone receptor expression, and thus, have an indirect effect on decidualization [63]. It has also been found that the endometrial layer of the uterus undergoes steroid-dependent (estrogen and progestin) cyclic changes in structure and function. After a proliferative and secretory phase, steroid support 
is withdrawn and the uterine epithelium is shed [64]. Swainsonine poisoning can increase the production of misfolded proteins and aggravate ER stress. Through indirect effects on ER stress and direct effects on hormone receptors, hormones act on early pregnancy decidualization adjustment. Members of the tumor necrosis factor (TNF) superfamily participate in the decidualized immune process during early pregnancy and play an important role in proliferation and differentiation. B-lymphocyte activating factor (BAFF) is a new member of the TNF superfamily. BAFFR protein is localized in the exosomes' decidual stromal cells, and experiments have shown that $\mathrm{E} 2+\mathrm{P} 4$ can significantly upregulate the expression of two factors [65]. Studies have shown that swainsonine can increase the activity of native oxygen species (NOS), thereby producing an advantageous TNF- $\alpha$ play $\check{T}$-cell phagocytosis, and a killing function. Swainsonine may exert a hormone antagonistic or synergistic action of impact family member of TNF, thereby affecting decidualization [66]. As a protein, $\mathrm{P} 4$ receptor, abnormality of glycoprotein modification caused by SW poisoning, is likely to affect its expression and synthesis, resulting in insufficient $\mathrm{P} 4$ receptors. Thus, ER stress-induced swainsonine affects the normal PGR expression of the progesterone secretion disorder, resulting in a change in decidualization. There are also studies that indicate that swainsonine can indirectly affect the normal effect of estrogen and progesterone by the immunization route. In summary, swainsonine poisoning may directly affect the hormone receptor, or may indirectly (through the immune and ER stress) affect the process of decidualization, and then cause decidual tissue denaturation, resulting in abortion.

\section{Effect of Swainsonine on Decidualization by Apoptosis}

\subsection{Apoptosis}

Apoptosis is considered a vital component of various processes including normal cell turnover, proper development and functioning of the immune system, hormone-dependent atrophy, embryonic development and chemical-induced cell death [67]. There are three stages of apoptosis. At the start of apoptosis, cells collapsed, cell connections and surface microvilli disappear, rough ER cysts expand, and chromosomes condense in the nucleus; the cell membrane structure remains intact. The next step is apoptotic body formation, which involves phosphatidylserine degradation of the cell membrane, nuclear membrane fragmentation of DNA fragments into small fragments, which aggregate, separate, and form single spore-like apoptotic body. During this phase, intracellular substances do not overflow outside the cell. In the third stage, apoptotic bodies are phagocytosed by tissue macrophages or adjacent cells, and there is no inflammatory reaction in this process. Apoptosis occurs under the control of multiple genes, which are highly conserved. Studies on apoptotic signal transduction pathways can be summarized as both death receptor and mitochondrial pathways (Figure 10). The apoptotic biochemical pathway is substantially similar in vertebrates, flies, and nematodes and ultimately relies on activation of the 

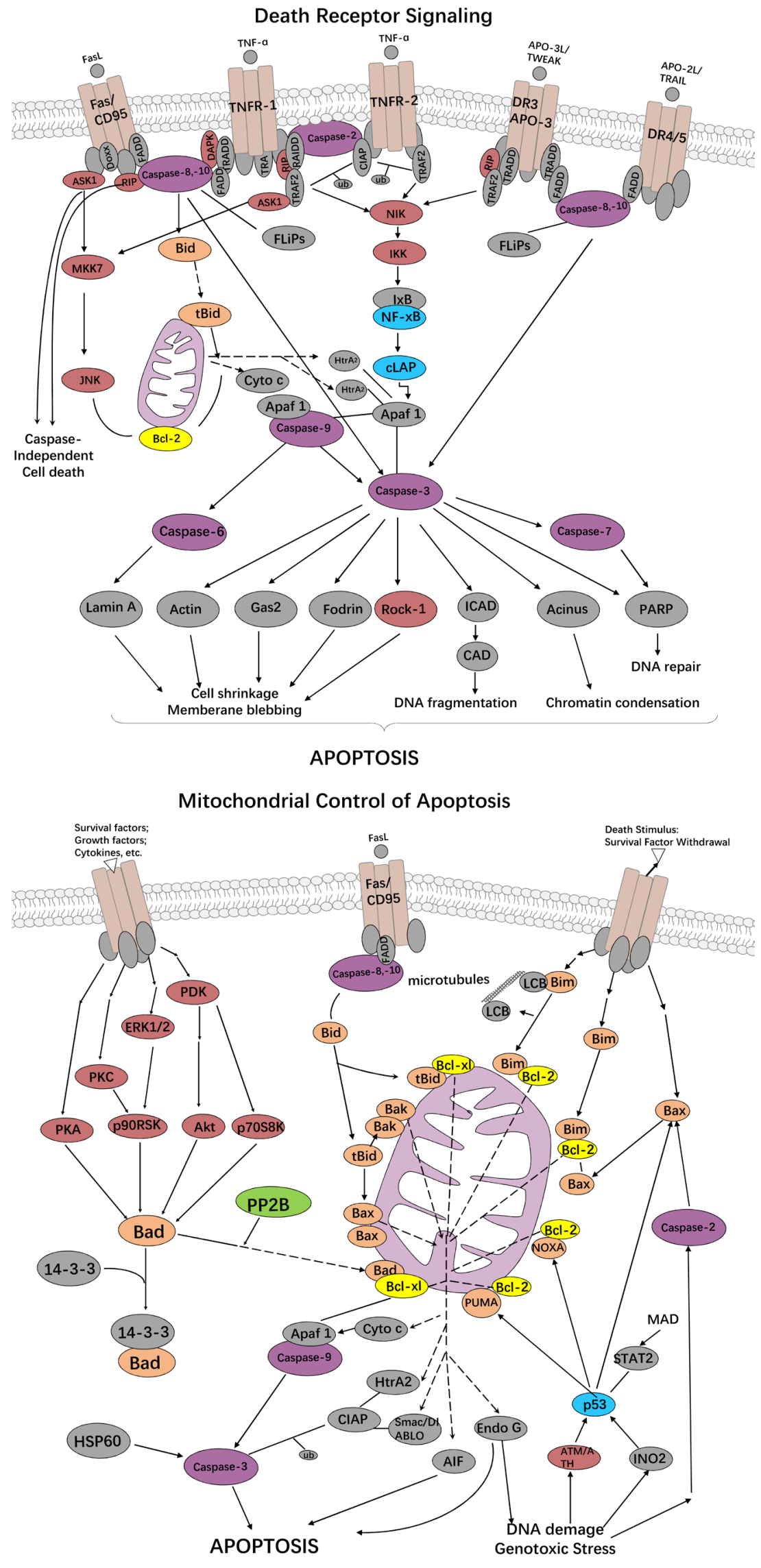
Overview: Regulation of Apoptosis

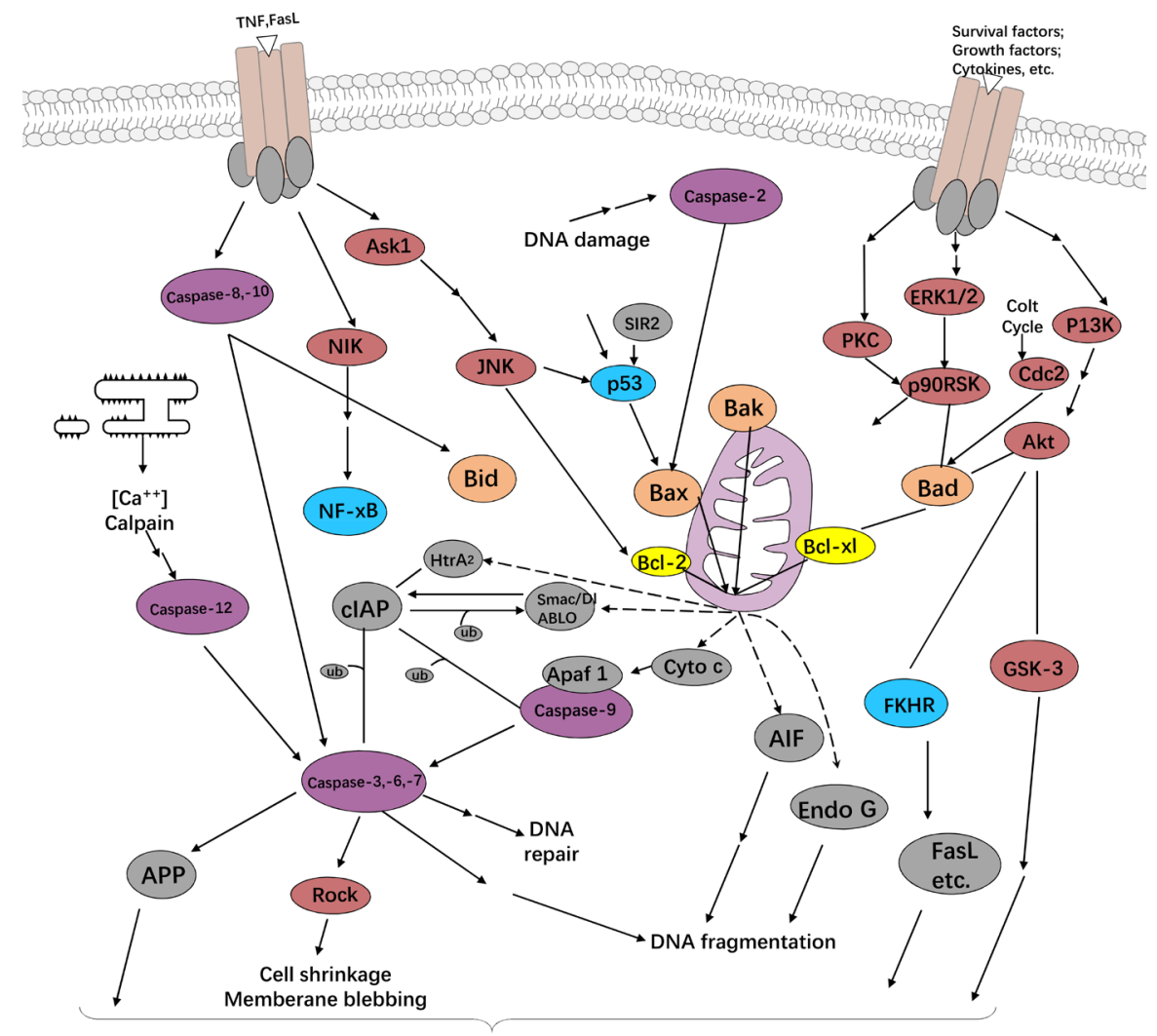

APOPTOSIS

Figure 10. Summary of apoptotic regulatory pathways; death receptor pathway of apoptosis; mitochondrial pathway of apoptosis [67].

caspase pathway or its analogues. Caspase is a class of cysteine aspartate-specific protease that plays a key role in the process of apoptosis. Its common active site is cysteine residues, aspartate residues, and peptide bonds. Normally, caspase is an inactive proenzyme consisting of an $\mathrm{N}$-terminal pre-region and a small subunit. When the apoptotic signal is stimulated, the peptide bond following the aspartic acid residue of the zymogen molecule breaks, exposing the active site, dissociating the large and small subunits, and polymerizing into an active tetrameric form [68].

Mitochondrial apoptosis pathway is also called endogenous apoptotic pathway. Mitochondria control the life and death of cells under aerobic conditions and are the main sites for cellular ATP production. Death receptor pathway: This pathway is an apoptotic pathway induced by extracellular signals and is therefore also referred to as an exogenous apoptotic pathway. There are at least 8 death receptors on the surface of mammalian cells: Fas, TNFR1, TNFR2, DR3, DR4, DR5, Dc R1, and Dc R2, all of which are members of the tumor necrosis factor alpha receptor family. The most typical of these death receptors are Fas and TNFRs. Endoplasmic reticulum pathway: At present, there are three pathways known to induce apoptosis of endoplasmic reticulum stress: 1) Activation 
of CHOP/GADD153 gene transcription; 2) JNK activation pathway; 3) Endoplasmic reticulum-specific Cysteine protease Caspase-12 activation pathway.

\subsection{Apoptosis and Decidualization}

In the primate menstrual cycle, the follicular atresia and the corpus luteum are parts of the process of apoptosis, and genital organs atrophying due to hormonal insufficiency will also undergo apoptosis. Apoptosis in reproductive organs and tissues during pregnancy is essential. However, abnormal apoptosis can result in abnormal pregnancy, causing various pathological phenomena, such as habitual abortion, gestational trophoblastic disease, and intrauterine growth retardation. During early pregnancy, endometrial decidualization, endometrial differentiation, and apoptosis limit trophoblast cells, so that they cannot over-invade the endometrium [69]. The specific process of decidualization is as follows: the blastocyst first adheres, and as implantation progresses, stromal cells surrounding the blastocyst begin to proliferate extensively, differentiate, and at the same time gain polyploidy, after which the stromal cells surrounding the blastocyst stop proliferation while differentiating again, forming a primary decidual zone. Next, cell apoptosis that occurred in the primary decidual zone disappeared until stromal cells in the decidual zone adjacent to the primary zone continue to proliferate and differentiate into a secondary decidual zone. Finally, cells in the secondary decidual zone also undergo apoptosis, increasing the space at the site of implantation to accommodate the growing embryo [70]. Thus, apoptosis is essential in decidual tissue formation.

There are many ways to trigger apoptosis in decidual tissue: most cyclins are activated protein-dependent kinases, which are involved in decidualized protein phosphorylation and are positive regulators of the cell cycle during decidualization. However, not all of the cyclins play a positive regulatory role in regulating the cell cycle. Cyclin G2, for example, induces apoptosis in endometrial cells with a negative effect on the cell cycle in decidualization [71]. Fas belongs to the TNF receptor family and initiates a series of downstream cascade reactions by activating caspase-8 (i.e., FLICE), leading to apoptosis. Throughout pregnancy, both trophoblast cells and syncytiotrophoblasts express Fas-L, the decidual precursor of Fas that binds to Fas-L on the surface of lymphocytes and trophoblast cells to trigger autologous apoptosis. Fas in early pregnancy decidua mainly distributed in the late are located on the cell surface placental trophoblasts [72]. Although apoptosis is necessary for the formation of decidual tissue, excessive apoptosis is not conducive to decidualization in early pregnancy.

\subsection{Swainsonine and Apoptosis and Decidualization}

Swainsonine poisoning can make caspase-3,9,12 increase to a certain extent, and can promote apoptosis in medium and high doses. Fas is also a member of the TNF superfamily, which quickly combines with its ligand to form apoptosis-inducing complex, activates the downstream caspase- 8 , and induces apoptosis. Thus, 
swainsonine has a certain influence on apoptosis, and can activate some apoptosis factors and induce apoptosis. There is a significant impact on the expression of apoptosis-related genes and proteins in swainsonine-poisoned animal tissues. Qiubo Yu, in early decidual tissue gene expression profiles and proteome results, shows that natural abortion decidual tissue compared with normal, apoptosis-related genes an increase of 55, a decrease of 27 [73]. Swainsonine can control cell self-apoptosis and induce gene-induced cell apoptosis. Swainsonine treatment led to varying degrees of apoptosis in goat placental trophoblast cells by activating the mitochondria-mediated pathway of death of caspase-9/-3 [74]. Treatment of human gastric cancer cell line SGC-7901 with different concentrations of swainsonine for 24 hours resulted in the upregulation of c-myc, a gene that promotes apoptosis, and the suppression of the expression of the apoptotic genes bc1-2 and p53 [75]. Swainsonine can downregulate mRNA expression and protein expression of Bax protein and upregulate XIAP; finally, cells undergoing Hep-2 mitochondrial pathway cause apoptosis. The rat BRL-3A cell line was exposed to swainsonine, and the results showed that swainsonine is involved in the induction of apoptosis in BRL-3A cells via death receptors and mitochondrial pathways. The mechanisms of swainsonine-induced apoptosis may relate to $\left[\mathrm{Ca}^{2+}\right]$ overloading and the expression of apoptosis-related genes, and an increase in the concentrations of $\left[\mathrm{Ca}^{2+}\right]$ is one of the leading causes of ER stress [76]. Therefore, swainsonine cannot only affect apoptosis by changing various factors that induce apoptosis, but also indirectly affect apoptosis through ER stress [77]. We conclude that swainsonine induces miscarriage by affecting either normal or early pregnancy decay directly or indirectly through apoptosis.

\section{Swainsonine, Endoplasmic Reticulum Stress, and Decidualization}

\subsection{Endoplasmic Reticulum Stress}

The ER is an important organelle that plays a key role not only in protein synthesis, folding, and secretion, but also in the lipid biosynthesis process [78]. Improperly folded or modified proteins accumulate in the ER lumen, and the resulting phenomenon is called ER stress. There are many situations in animal life that can trigger ER-stress reactions, such as gene mutations, calcium imbalance, oxidative stress, inflammatory response, and hypoxia. Similarly, ER stress occurs when the homeostasis of cells is unbalanced, such as in accelerated protein synthesis, autophagy disorders, insufficient energy supply, overnutrition, or inadequate nutrition [79]. There are many diseases that are ER-stress-related, such as neurodegenerative diseases, diabetes, cancer, and hyperglycemia. In addition, inflammatory reactions may induce ER stress [80]. ER stress inhibitors can downregulate the level of apoptosis induced by palmitate in vascular endothelial cells, which means that the ER-stress signaling pathway plays an important role in preventing apoptosis of vascular endothelial cells induced by palmitate. Excessive alcohol consumption may induce breast cancer cells to have ER stress, 
which can promote malignancy. The stresslin gene, which is upregulated by ER stress, plays an important role in the pathogenesis of ER stress-mediated neurodegenerative diseases. ER stress also mediates non-esterified fatty acids (NEFA)-induced insulin resistance, and IRE1 $\alpha$, a signaling pathway associated with ER stress response can also mediate NEFAs-induced hepatic primary cell insulin resistance by activating JNK [81] [82]. There are a number of quality control mechanisms in the ER that ensure protein transport, proper folding, modification and assembly. To recover protein-folding capacity and ER homeostasis, cells initiate a conserved signal transduction pathway termed the unfolded protein response (UPR), sensing to ER stress by sophisticated surveillance systems [83]. The physiological function of UPR is to maintain the accurate functioning of ER function and to control the amount of intracellular protein [84] (Figure 11). When ER stress is absent in cells, glucose chaperone 78 (GRP78) and other chaperones associated with ER-stress signaling pathways in the three cells inactivate, leaving the three pathways inactive. When ER stress occurs, these three pathways have been activated and regulate the expression of related Genetic disorders and neurodegenerative diseases

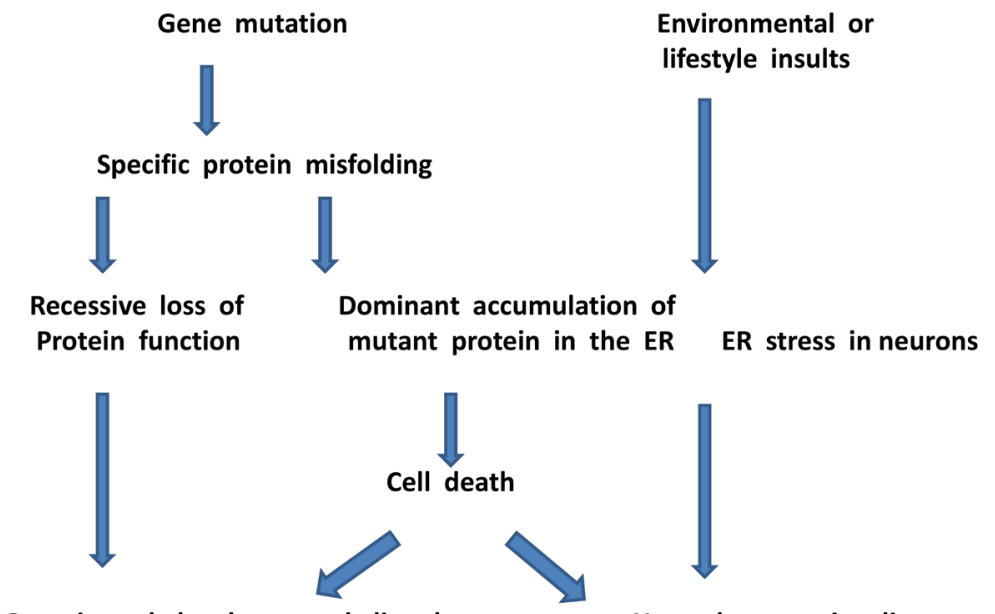

Genetic and developmental disorders

Neurodegenerative diseases

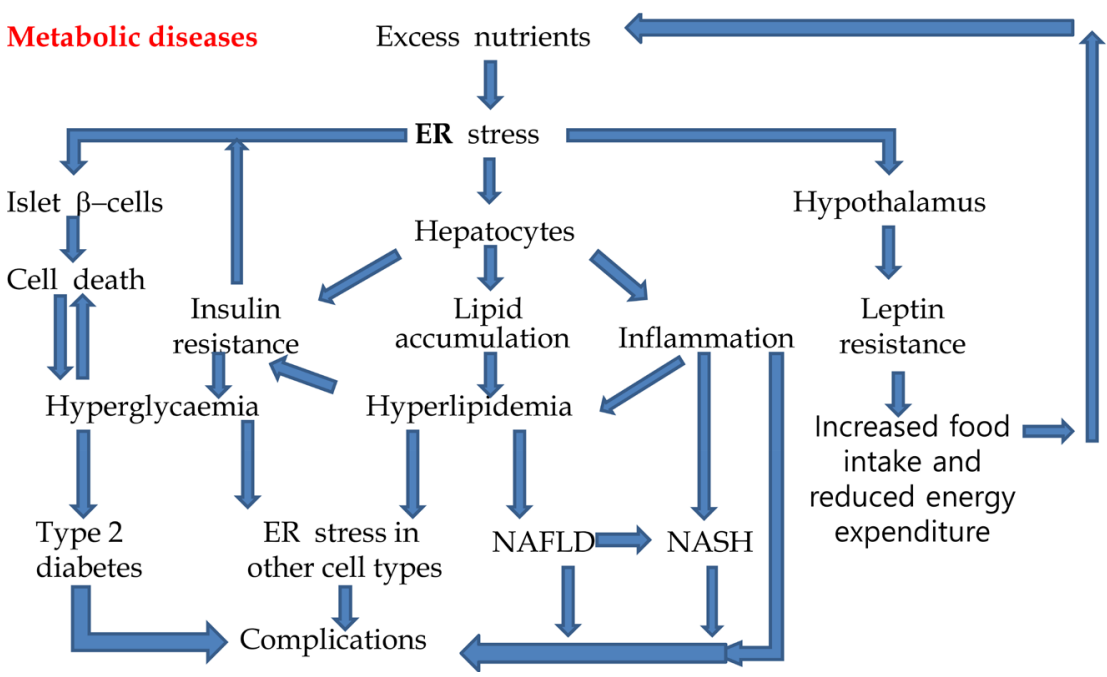




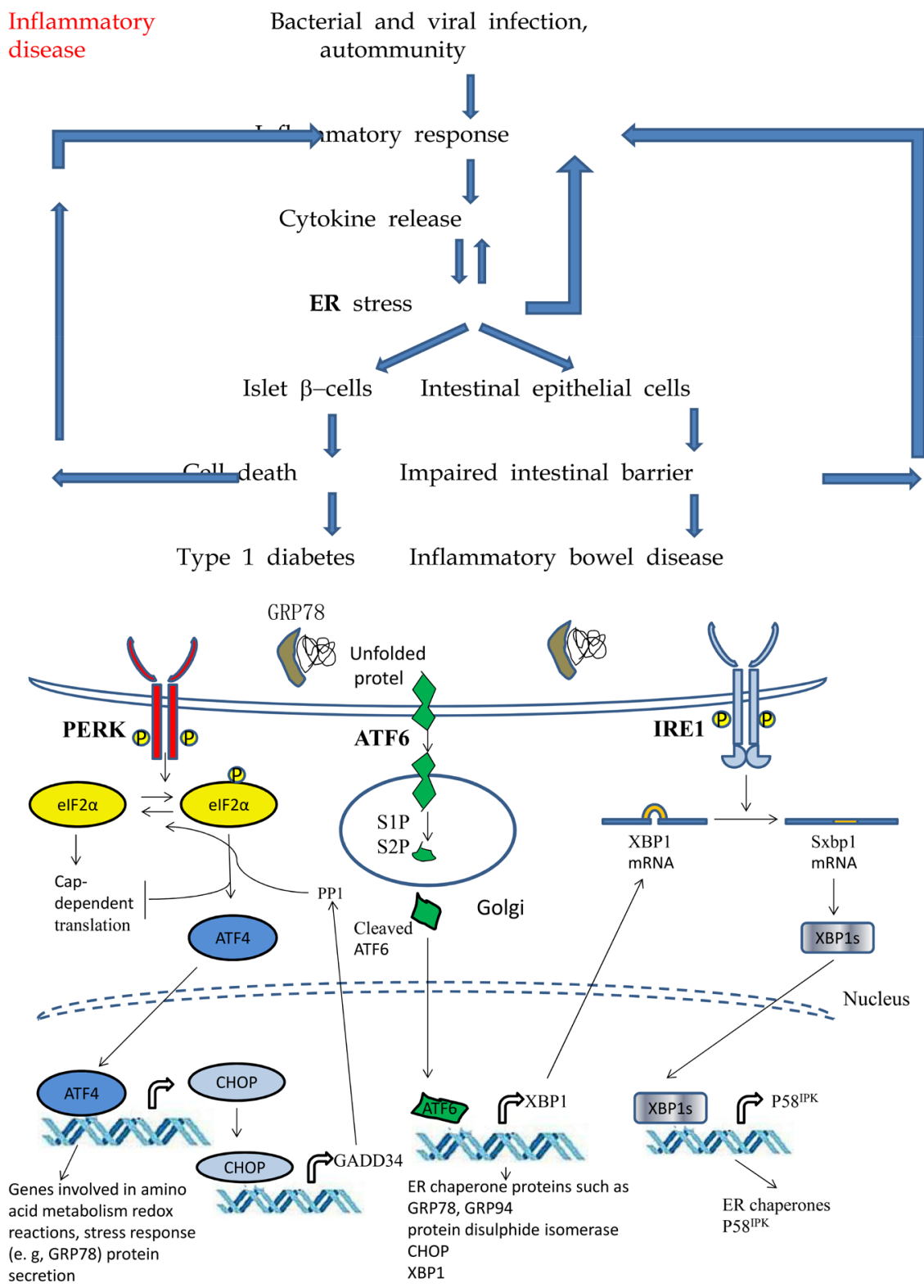

Figure 11. ER-stress-related genetic and neurodegenerative diseases, metabolic diseases and inflammatory diseases (top left, top right, bottom left); UPR signaling in eukaryotes (bottom right) [85] [86].

proteins. The three pathways are pancreatic ER kinase (PERK), activating transcription factor 6 (ATF6), and inositol requiring enzyme 1 a (IRE1a), which is the endoplasmic reticulum stress repair pathway.

ER stress and UPR activation have important roles in the pathogenesis of many diseases. The induction of ER stress in vivo is attributable to both intrinsic and extrinsic factors. For example, gene mutations can cause defects in the folding and transport of certain proteins. The loss of function and toxicity that is associated with the accumulation of mutant protein in the ER leads to genetic and developmental disorders and neurodegenerative diseases. Environmental or lifestyle insults that trigger ER stress in neurons also contribute to the develop- 
ment of neurodegenerative diseases. More often, however, environmental insults such as an excess of nutrients or inflammation induce protein misfolding in the ER, which compromises cell function and triggers cell death and the development of metabolic and inflammatory diseases. NASH, non-alcoholic steatohepatitis. The UPR is mediated by three ER stress sensors. Binding of unfolded proteins to GRP78 within the ER lumen allows activation of PERK, ATF6 and IRE1. PERK dimerises and autophosphorylates. It phosphorylates eIF2 $\alpha$ and thus general Cap-dependent translation is inhibited. Cap-independent translation allows the translation of certain proteins such as ATF4 which activates CHOP transcription. One of the genes induced by CHOP is GADD34 which regulates protein phosphatase 1 (PP1), which can dephosphorylate eIF2 $\alpha$. Activation of ATF6 allows its translocation to the Golgi where it undergoes cleavage by S1P and S2P proteases. Cleaved ATF6 activates XBP1 transcription. Active IRE1 is a dual kinase and endonuclease. One of its targets is XBP1 mRNA which undergoes splicing to produce an active transcription factor, XBP1s. One of the targets of $\mathrm{XBP} 1 \mathrm{~s}$ is $\mathrm{p} 58^{\mathrm{IPK}}$.

\subsection{Endoplasmic Reticulum Stress and Decidualization}

ER stress has a wide range of roles in mammalian reproduction, including the formation of decidualization, which is important for embryo implantation. Many ER-stress-related gene expressions change during embryo implantation, suggesting that ER stress may be an essential step in embryo implantation. On day 5 of pregnancy in mice, the GRP78 protein was more highly observed around the implanted embryo at the implantation site, and we understand that the change of GRP78 expression means the occurrence of ER stress [87]. On the other hand, calcium homeostasis can cause ER stress, and ER stress and UPR regulate calcium homeostasis [88]. Studies have shown that expression of ER-stress-related genes in the uterus is decreased in calcium-binding protein-D(9k) and $-\mathrm{D}(28 \mathrm{k})$ knockout mice, and $\mathrm{S} 100 \mathrm{P}$ is upregulated in uterine epithelium during embryo implantation. Conversely, if calcium-binding protein S100A11 is downregulated, embryos cannot implant. All of these indicate that calcium is involved in ER stress and regulates embryo implantation [89]. Therefore, it is proved that calcium ions may affect early pregnancy decidualization through ER stress and UPR, thereby regulating the successful implantation of embryos.

\subsection{Swainsonine Endoplasmic Reticulum Stress and Decidualization}

The most important reason that swainsonine causes animal poisoning is as an inhibitor of $\alpha$-mannosidase activity, which affects the glycosylation process and causes the accumulation of oligosaccharides. The effect on glycosylation will inevitably lead to abnormal glycoprotein synthesis, and may lead to ER stress. Second, $\alpha$-mannosidases play an important role in protein degradation and are selectively degraded when proteins are incorrectly folded, mutated, processed, or 
modified in the ER [90]. Lysosomal degradation is the main site of the glycoprotein. After abnormal glycoproteins are transported to the lysosomes, a part of them are degraded through the cytoplasm way, but mostly are via hydrolytic enzymes [91]. Inhibition of $\alpha$-mannosidase activity leads to misfolding of proteins that are difficult to hydrolyze, exacerbating ER stress, and that UPR has a negative effect on the recovery of ER stress. In the meantime, an important function of $\mathrm{N}$-glycans is to help the nascent peptide to properly fold and to stabilize the spatial conformation of the mature glycoprotein. Inhibition of $\alpha$-mannosidase, affecting the processing of $\mathrm{N}$-glycans, and thereby affecting the stability of protein folding, accumulates a significant amount of wrongly processed proteins, which in itself may be an important cause of ER stress. Studies have shown that one of the causes of ER stress induced by the downregulation of GnT-V expression in human hepatocarcinoma cell line 7721 is the alteration of glucose transporter $\mathrm{N}$-glycan glycosylation (the decrease in the number of three- or four-antenna N-glycans) and decreased transport activity [92]. This happens because decreased glucose transporter activity leads to glucose starvation in cells, triggering ER stress. Swainsonine can cause an increase in cytoplasmic $\mathrm{Ca}^{2+}$ concentration and is one of the causes of ER stress [93]. Severe ER stress may lead to abnormal decidualization in early pregnancy, which interrupts pregnancy. This may be the reason why pregnant dams tend to miscarry during pregnancy after being infected with swainsonine. Swainsonine may affect ER stress during decidualization, whereas the ER-stress pathway may induce the expression of P4, whereas E2 may regulate the expression of the P4 receptor and GRP78 in the rat uterus. GRP78 is the internal sign of stress in cytoplasm. Swainsonine also has an effect on apoptosis, which may be related to the increase of $\mathrm{Ca}^{2+}$ concentration. $\mathrm{Ca}^{2+}$ overload can induce ER stress. Both apoptosis and ER stress are essential for early pregnancy decidualization. In conclusion, the causes of miscarriage due to swainsonine poisoning may include directly affecting the abnormal decidualization caused by ER stress; the ER stress leading to abnormal ecdysone secretion; ER stress variation caused by hormone disorders; and ER stress induced indirectly by apoptosis leading to abnormal decidualization and other factors.

\section{Other Factors}

Normal decidual tissue consists of many cells, such as extra-trophoblast cells, endometrial cells, and bone-marrow-derived cells, including $\mathrm{T}$ cells and a small number of B cells [94]. Many studies have shown that low doses of swainsonine can improve the body's immune function, promote immune effector cell proliferation and bone marrow cell proliferation, and promote bone marrow cell differentiation. Oxytropis kansuensis Bunge alkaloids can affect the mouse blood immune cell activity in low doses, but also can improve the spleen, thymus, and other immune organ growth index. Low doses of swainsonine can increase animal T-lymphocyte proliferation and $\mathrm{CD} 4+/ \mathrm{CD} 8+$ ratio. However, once a toxic 
dose of swainsonine is reached, the T-lymphocyte proliferation and CD4+/CD8+ organ growth index ratio are severely reduced [95]. At the same time, studies have shown that early abortion decidua tissue compared to the normal decidua tissue immune response related genes upregulated 41 and downregulated 25, indicating that the body's immune capacity and decidualization are closely related. This also means that in the case of swainsonine poisoning, the number of $\mathrm{T}$ lymphocytes and B lymphocytes in animals decreases, and the immune function changes simultaneously. Changes in $\mathrm{T}$ lymphocytes and B lymphocytes that are part of the decidua tissue may affect normal membrane processes. Dong Feng also found that the concentration of more than $0.8 \mu \mathrm{g} / \mathrm{mL}$ of swainsonine may downregulate the expression of cyclin E and cyclin D1 and protein-dependent protein kinase to block the cell cycle in the G0/G1 phase, whereas CDK6, and both cyclin D3 and P21, regulate the differentiation and polyploidization of decidual cells, and their downregulation will greatly affect normal decidualization [96].

\section{Conclusion}

To sum up, the main causes of dam abortion caused by swainsonine poisoning are the following. First, swainsonine acts through a variety of pathways to change the secretion of early pregnancy hormones, affecting the process of decidualization. Second, swainsonine directly or indirectly affects the decidual cell apoptosis caused by decidual changes. Third, swainsonine directly or indirectly causes ER stress, leading to abnormal decidualization. Fourth, some other factors, including immune factors and cell cycle changes, lead to abnormal decidualization. These four reasons are all due to the influence of swainsonine on glycan processing and glycosylation modification. Glycosylation modification is an indispensable factor in the process of synthesis, secretion, binding, and function of glycoprotein. Swainsonine disturbance to this process can directly or indirectly affect ER stress, apoptosis, hormone disorders, immune dysfunction, cell cycle disorders, and other pathways, triggering abnormal pregnancy decidualization, and then leading to the poisoning of animals and abortion.

\section{Fund Project}

National natural science foundation-youth project (31302153), Shaanxi provincial natural science foundation-youth project (2017JQ3012).

\section{Conflicts of Interest}

The authors declare no conflicts of interest regarding the publication of this paper.

\section{References}

[1] Tong, D.W. (2001) Immunogenicity of Swainsonine-BSA. Journal of Northwest A\&F University (Natural Science Edition), No. 4, 1. 
[2] Ralphs, M.H., Graham, D., Molyneux, R.J., et al. (1993) Seasonal Grazing of Locoweeds by Cattle in Northeastern New Mexico. Journal of Range Management, 46, 416-420. https://doi.org/10.2307/4002659

[3] Li, Q.F., Wang, J.H., Qi, X.R., Tan, Y.Y. and Yan, G.X. (2001) Analysis of Hematological Indexes of Glacial Oxytropis in Goats. Journal of Northwest A\&F University (Natural Science Edition), 1, 97-99.

[4] Wang, X. (2011) Isolation of Swainsonine-Degrading Bacteria HW 08 and Its Characteristics. Northwest A\&F University, Yangling.

[5] Wang, X. (2014) The Cytotoxicity of BRL-3A Induced by Swainsonine and the Protective Effect of "Schizophora E" and Fe 2+. Northwest A\&F University, Yangling.

[6] Cui, H.B. (2008) Thirty Years of "Flora of China" I Have Experienced. Chinese Journal of History of Science and Technology, 73-89+119.

[7] Thompson, D.C., Knight, J.L., Sterling, T.M., et al. (1995) Preference for Specific Varieties of Woolly Locoweed by a Specialist Weevil. Cleonidius trivittatus Southwestern Entomologist, 20, 325-333.

[8] Wu, C.C., Zhao, B.Y., Lu, H., et al. (2014) Dynamic Changes of Swainsonine in the Main Locoweeds in China. Northwestern Agricultural Journal, 23, 51-58.

[9] Colegate, S.M., Dorling, P.R. and Huxtable, C.R. (1979) A Spectroscopic Investigation of Swainsonine: An $\alpha$-Mannosidase Inhibitor Isolated from Swainsona canescens. Australian Journal of Chemistry, 32, 2257-2264. https://doi.org/10.1071/CH9792257

[10] Rong, J. (2011) Effects of Oxytropis Gansu on Subacute Toxicity and Distribution and Expression of $\alpha$-Mannosidase in Rats. Northwest Agriculture and Forestry University, Yangling.

[11] Yang, M.Q. and Cao, G.R. (1997) The Toxicity, Metabolism and Use of Swainsonine. Progress in Animal Medicine, 17, 22-27.

[12] Richards, J.B., Hallford, D.M. and Duff, G.C. (1999) Serum Luteinizing Hormone, Testosterone, and Thyroxine and Growth Responses of Ram Lambs Fed Locoweed (Oxytropis sericea) and Treated with Vitamin E/selenium. Theriogenology, 52, 1055-1066. https://doi.org/10.1016/S0093-691X(99)00194-6

[13] James, L.F., Shupe, J.L., Binns, W. and Keeler, R.F. (1967) Abortive and Teratogenic Effects of Locoweed on Sheep and Cattle. American Journal of Veterinary Research, 126, 1379-1388.

[14] Wang, L. and Suzuki, T. (2013) Dual Functions for Cytosolic a-Mannosidase (Man2C1): Its Downregulation Causes Mitochondria-Dependent Apoptosis Independently of Its a-Mannosidase Activity. The Journal of Biological Chemistry, 17, 11887-11896. https://doi.org/10.1074/jbc.M112.425702

[15] Hao, B.C. (2017) Study on the Development of Detoxification Drugs for Livestock Locoweed Poisoning and the Antiviral Mechanism of Swainsonine, the Active Ingredient in Locoweed. Gansu Agricultural University, Lanzhou.

[16] Stanley, P. (2011) Golgi Glycosylation. Cold Spring Harbor Perspectives in Biology, 3, pii: a005199.

[17] Torres, C.R. and Hart, G.W. (1984) Topography and Polypeptide Distribution of Terminal N-Acetylglucosamine Residues on the Surfaces of Intact Lymphocytes. Evidence for O-Linked GlcNAc. The Journal of Biological Chemistry, 259, 3308-3317.

[18] Cantarel, B.L., Coutinho, P.M., Rancurel, C., Bernard, T., Lombard, V. and Henrissat, B. (2009) The Carbohydrate-Active EnZymes Database (CAZy): An Expert Re- 
source for Glycogenomics. Nucleic Acids Research, 37, D233-D238.

https://doi.org/10.1093/nar/gkn663

[19] Dias Wagner, B., Cheung Win, D., Wang, Z. and Hart Gerald, W. (2009) Regulation of Calcium/Calmodulin-Dependent Kinase IV by O-GlcNAc Modification. Journal of Biological Chemistry, 284, 21327-21337. https://doi.org/10.1074/jbc.M109.007310

[20] Caldwell, S.A., Jackson, S.R., Shahriari, K.S., Lynch, T.P., Sethi, G., Walker, S., Vosseller, K. and Reginato, M.J. (2010) Nutrient Sensor O-GlcNAc Transferase Regulates Breast Cancer Tumorigenesis through Targeting of the Oncogenic Transcription Factor FoxM1. Oncogene, 29, 2831-2842. https://doi.org/10.1038/onc.2010.41

[21] Hanover, J.A., Forsythe, M.E., Hennessey, P.T., Brodigan, T.M., Love, D.C., Ashwell, G. and Krause, M. (2005) A Caenorhabditis Elegans Model of Insulin Resistance: Altered Macronutrient Storage and Dauer Formation in an OGT-1 Knockout. Proceedings of the National Academy of Sciences, 102, 11266-11271. https://doi.org/10.1073/pnas.0408771102

[22] Rexach, J.E., Clark, P.M. and Hsieh-Wilson, L.C. (2008) Chemical Approaches to Understanding O-G1cNAc Glycosylation in the Brain. Nature Chemical Biology, 4, 97-106. https://doi.org/10.1038/nchembio.68

[23] Li, S., Mo, C., Peng, Q., Kang, X., Sun, C., Jiang, K., Huang, L., Lu, Y., Sui, J., Qin, X. and Liu, Y. (2013) Cell Surface Glycan Alterations in Epithelial Mesenchymal Transition Process of Huh7 Hepatocellular Carcinoma Cell. PLoS ONE, 8, e71273. https://doi.org/10.1371/journal.pone.0071273

[24] Santos, I.C., Silbiger, V.N., Higuchi, D.A., Gomes, M.A., Barcelos, L.S., Teixeira, M.M., Lopes, M.T., Cardoso, V.N., Lima, M.P., Araujo, R.C., Pesquero, J.B. and Pesquero, J.L. (2010) Angiostatic Activity of Human Plasminogen Fragments Is Highly Dependent on Glycosylation. Cancer Science, 101, 453-459. https://doi.org/10.1111/j.1349-7006.2009.01403.x

[25] Rose, D.R. (2012) Structure, Mechanism and Inhibition of Golgi $\alpha$-Mannosidase II. Current Opinion in Structural Biology, 22, 558-562. https://doi.org/10.1016/j.sbi.2012.06.005

[26] Dohi, K., Isoyama-Tanaka, J., Misaki, R. and Fujiyama, K. (2011) Jack Bean Alpha Mannosidase Digestion Profile of Hybrid-Type N-Glycans: Effect of Reaction $\mathrm{pH}$ on Substrate Preference. Biochimie, 93, 766-771. https://doi.org/10.1016/j.biochi.2011.01.005

[27] Shigenobu, Y., Yuko, W., Toshiyuki, W., Akira, N. and Mai, S. (2010) Alpha-Catenin as a Tension Transducer That Induces Adherens Junction Development. Nature Cell Biology, 12, 533-542. https://doi.org/10.1038/ncb2055

[28] Kuntz, D.A., Nakayama, S., Shea, K., Hori, H., Uto, Y., Nagasawa, H. and Rose, D.R. (2010) Structural Investigation of the Binding of 5-Substituted Swainsonine Analogues to Golgi Alpha-Mannosidase II. ChemBioChem, 11, 673-680. https://doi.org/10.1002/cbic.200900750

[29] Olga, V., Elmira, T., Iskandar, Y., Eugenia, S. and George, S. (2007) Inverse Correlation between the Extent of N-Glycan Branching and Intercellular Adhesion in Epithelia. Contribution of the Na,K-ATPase betal Subunit. Journal of Biological Chemistry, 283, 2192-2202.

[30] Zhang, S., Zhao, H. and Chen, H. (2017) Effect of Swainsonine on the Expression of N-Glycans in Osteosarcoma Cancer Stem Cells. Practical Journal of Medicine, 33, 41-43.

[31] Shawn, B., Baker Christopher, A., Emery, S., Mahal Sukhvir, P., Herva Maria, E., 
Demczyk Cheryl, A., Li, J. and Charles, W. (2011) Abrogation of Complex Glycosylation by Swainsonine Results in Strain- and Cell-Specific Inhibition of Prion Replication.

[32] James, J.F. and Wilson, I.C. (1972) Lithium Therapy in Manic States: Prediction of Therapeutic Effect. Activitas Nervosa Superior, 14, 52-57.

[33] Leibiger, H., Kersten, B., Albersheim, P. and Darvill, A. (2000) Effect of Somatic Hypermutation on Potential N-Glycosylation Sites in Human Immunoglobulin Heavy Chain Variable Regions. Molecular Immunology, 37, 107-113. https://doi.org/10.1016/S0161-5890(00)00038-9

[34] Osamu, S., Yoshihiro, N. and Masafumi, A. (2004) Regulatory Roles of $\mathrm{N}-$ Glycosylation of Immunoglobulin M in CD40-CD40L-Mediated Cell Survival of Human Diffuse Large B Cell Lymphoma. Oncology Reports, 11, 1031-1039.

[35] Suzuki, O. and Abe, M. (2014) Galectin-1-Mediated Cell Adhesion, Invasion and Cell Death in Humananaplastic Large Cell Lymphoma: Regulatory Roles of Cell Surface Glycans. International Journal of Oncology, 44, 1433-1442. https://doi.org/10.3892/ijo.2014.2319

[36] Crispin, M., Aricescu, A.R., Chang, V.T., Jones, E.Y., Stuart, D.I., Dwek, R.A., Davis, S.J. and Harvey, D.J. (2007) Disruption of Alpha-Mannosidase Processing Induces Non-Canonical Hybrid-Type Glycosylation. FEBS Letters, 581, 1963-1968. https://doi.org/10.1016/j.febslet.2007.04.020

[37] Dey, S.K., Lim, H., Das, S.K., Reese, J., Paria, B.C., Daikoku, T. and Wang, H. (2004) Molecular Cues to Implantation. Endocrine Reviews, 25, 341-373. https://doi.org/10.1210/er.2003-0020

[38] Padmanabhan, R.A. and Laloraya, M. (2016) Estrogen-Initiated Protein Interactomes during Embryo Implantation. American Journal of Reproductive Immunology, 75, 256-262. https://doi.org/10.1111/aji.12455

[39] Lim, H.J. and Wang, H. (2010) Uterine Disorders and Pregnancy Complications: Insights from Mouse Models. Journal of Clinical Investigation, 120, 1004-1015. https://doi.org/10.1172/JCI41210

[40] Van Soom, A., Wydooghe, E., Heras, S. and Vandaele, L. (2011) Alternative Models for the Study of Embryo-Maternal Cross-Talk and Signaling Molecules from Fertilisation to Implantation. Reproduction, Fertility and Development, 23, 3-5.

[41] Sharma, S., Godbole, G. and Modi, D. (2016) Decidual Control of Trophoblast Invasion. American Journal of Reproductive Immunology, 75, 341-350. https://doi.org/10.1111/aji.12466

[42] Ramathal, C.Y., Bagchi, I.C., Taylor, R.N. and Bagchi, M.K. (2010) Endometrial Decidualization: Of Mice and Men. Seminars in Reproductive Medicine, 28, 17-26.

[43] Qi, Q.R., Zhao, X.Y., Zuo, R.J., Wang, T.S., Gu, X.W., Liu, J.L. and Yang, Z.M. (2015) Involvement of Atypical Transcription Factor E2F8 in the Polyploidization during Mouse and Human Decidualization. Cell Cycle, 14, 1842-1858. https://doi.org/10.1080/15384101.2015.1033593

[44] Padmanabhan, R.A. and Laloraya, M. (2016) Estrogen-Initiated Protein Interactomes during Embryo Implantation. American Journal of Reproductive Immunology, 75, 256-262. https://doi.org/10.1111/aji.12455

[45] Wang, H.B. and Dey, S.K. (2006) Roadmap to Embryo Implantation: Clues from Mouse Models. Nature Reviews Genetics, 7, 185-199. https://doi.org/10.1038/nrg1808

[46] Li, H., Li, M. and Li, D. (2012) Regulatory Mechanism of Endometrial Decidualiza- 
tion. Reproduction and Contraception, 32, 259-263.

[47] Jiang, L. (2016) Effects of Different Concentrations of Dehydroepiandrosterone on Proliferation of Rat Endometrial Stromal Cells and Expression of dPRP mRNA. Guangxi Medical University.

[48] Warner, M. and Gustafsson, J.A. (2015) DHEA-A Precursor of ERbeta Ligands. The Journal of Steroid Biochemistry and Molecular Biology, 145, 245-247. https://doi.org/10.1016/j.jsbmb.2014.08.003

[49] Xu, J., Li, M., Zhang, L., Xiong, H., Lai, L., Guo, M., Zong, T., Zhang, D., Yang, B., Wu, L., Tang, M. and Kuang, H. (2015) Expression and Regulation of Androgen Receptor in the Mouse Uterus during Early Pregnancy and Decidualization. Molecular Reproduction and Development, 82, 898-906. https://doi.org/10.1002/mrd.22532

[50] Ezoe, K., Daikoku, T., Yabuuchi, A., Murata, N., Kawano, H., Abe, T., Okuno, T., Kobayashi, T. and Kato, K. (2014) Ovarian Stimulation Using Human Chorionic Gonadotrophin Impairs Blastocyst Implantation and Decidualization by Altering Ovarian Hormone Levels and Downstream Signaling in Mice. Molecular Human Reproduction, 20, 1101-1116. https://doi.org/10.1093/molehr/gau065

[51] Chen, Q., Peng, H., Zhang, Y., et al. (2009) Review and Prospect of Embryo Implantation Research. Scientific Bulletin, No. 18, 2771-2782.

[52] Conneely, O.M., Mulac-Jericevic, B. and Lydon, J.P. (2003) Progesterone-Dependent Regulation of Female Reproductive Activity by Two Distinct Progesterone Receptor Isoforms. Steroids, 68, 771-778.

https://doi.org/10.1016/S0039-128X(03)00126-0

[53] Lydon, J.P., DeMayo, F.J., Funk, C.R., Mani, S.K., Hughes, A.R., Montgomery, C.A., Shyamala, G., Conneely, O.M. and O’Malley, B.W. (1995) Mice Lacking Progesterone Receptor Exhibit Pleiotropic Reproductive Abnormalities. Genes \& Development, 9, 2266-2278. https://doi.org/10.1101/gad.9.18.2266

[54] Yao, R. (2011) Study on Progesterone Receptor, TNF- $\alpha$, IL- $1 \beta$ and NF- $\kappa B$ Changes in Decidual Cells Caused by Spontaneous Abortion. Central South University.

[55] Xu, L. and Tang, H. (2004) Effect of Mifepristone on Apoptosis Regulatory Genes and PR ER of Human Decidua in Early Pregnancy. Chinese Maternal and Child Health Care, 32-33.

[56] Brosens, J.J., Hayashi, N. and White, J.O. (1999) Progesterone Receptor Regulates Decidual Prolactin Expression in Differentiating Human Endometrial Stromal Cells. Endocrinology, 140, 4809-4820. https://doi.org/10.1210/endo.140.10.7070

[57] Yang, Y., Jin, Y., Lin, P., Hu, L., Cui, C., Li, X., Li, Q. and Wang, A. (2013) The Expression and Localization of LRF in the Female Reproductive Tract of Cycling Mice throughout the Estrous Cycle. Journal of Immunoassay and Immunochemistry, 34, 313-322. https://doi.org/10.1080/15321819.2012.732169

[58] Liang, G., Audas, T.E., Li, Y., Cockram, G.P., Doug, D.J., Martyn, A.C., Kokame, K. and Lu, R. (2006) Luman/CREB3 Induces Transcription of the Endoplasmic Reticulum (ER) Stress Response Protein Herp through an ER Stress Response Element. Molecular and Cellular Biology, 26, 7999-8010. https://doi.org/10.1128/MCB.01046-06

[59] Li, X. (2016) Role of Endoplasmic Reticulum Stress Regulator Protein LRF in Decidualization of Mouse Endometrium. Northwest Agriculture and Forestry University.

[60] Audas, T.E., Li, Y., Liang, G. and Lu, R. (2008) A Novel Protein, Luman/CREB3 Recruitment Factor, Inhibits Luman Activation of the Unfolded Protein Response. 
Molecular and Cellular Biology, 28, 3952-3966. https://doi.org/10.1128/MCB.01439-07

[61] Park, H.-J., Park, S.-J., Koo, D.-B., Lee, S.-R., Kong, I.-K., Ryoo, J.-W., Park, Y.-I., Chang, K.-T. and Lee, D.-S. (2014) Progesterone Production Is Affected by Unfolded Protein Response (UPR) Signaling during the Luteal Phase in Mice. Life Sciences, 113, 60-67. https://doi.org/10.1016/j.lfs.2014.07.033

[62] Yu, G. (2010) Effects of Progesterone Levels on Decidualization of Mouse Endometrium and Three-Dimensional Reconstruction of Its Morphology. China Union Medical College.

[63] Kurita, T., Lee, K., Saunders, P.T., et al. (2001) Regulation of Progesterone Receptors and Decidualization in Uterine Stroma of the Estrogen Receptor-Alpha Knockout Mouse. Biology of Reproduction, 64, 272-283. https://doi.org/10.1095/biolreprod64.1.272

[64] Narkar, M., Kholkute, S. and Nandedkar, T. (2006) Hormonal Regulation of Apoptosis in the Endometrium of Common Marmosets (Callithrix jacchus). Theriogenology, 66, 1194-1209. https://doi.org/10.1016/j.theriogenology.2006.03.032

[65] Wei, Y. (2009) Effects of Estrogen and Progestin on Expression of BAFFR and Bcl-2/Bax in Human Early Pregnancy Decidual Stromal Cells. Shan Dong University.

[66] Zhang, Z., Wang, J., Zhao, X., Yu, Y., Liu, Z., Yan, G., Ma, B. and Zhao, X. (2008) Effect of Swainsonine on Cellular Immune Function in Mice. Journal of Northwest A\&F University (Natural Science Edition), 61-66.

[67] Elmore, S. (2007) Apoptosis: A Review of Programmed Cell Death. Toxicologic Pathology, 35, 495-516. https://doi.org/10.1080/01926230701320337

[68] Marc, P., Sue, B., Marsden, V.S., Huang, D.C.S., Metcalf, D., Harris, A.W. and Strasser, A. (2005) FADD and Caspase-8 Are Required for Cytokine-Induced Proliferation of Hemopoietic Progenitor Cells. Blood, 106, 1581-1589. https://doi.org/10.1182/blood-2005-01-0284

[69] Salamonsen, L.A., Dimitriadis, E., Jones, R.L. and Nie, G. (2003) Complex Regulation of Decidualization: A Role for Cytokines and Proteases-A Review. Placenta, 24, S76-S85.

[70] Tan, Y., Li, M., Cox, S., Davis, M.K., Tawfik, O., Paria, B.C. and Das, S.K. (2003) HB-EGF Directs Stromal Cell Polyploidy and Decidualization via Cyclin D3 during Implantation. Developmental Biology, 265, 181-195. https://doi.org/10.1016/j.ydbio.2003.09.019

[71] Dong, X., Hu, D. and Qian, K. (2012) Progress in Regulating Endometrial Decidualization by Cell Cycle Regulators. Journal of Huazhong University of Science and Technology (Medical Edition), 41, 639-642.

[72] Moore, P.A., Belvedere, O., Orr, A., Pieri, K., LaFleur, D.W., Feng, P., Soppet, D., Charters, M., Gentz, R., Parmelee, D., Li, Y., Galperina, O., Giri, J., Roschke, V., Nardelli, B., Carrell, J., Sosnovtseva, S., Greenfield, W., Ruben, S.M., Olsen, H.S., Fikes, J. and Hilbert, D.M. (1999) BLyS: Member of the Tumor Necrosis Factor Family and B Lymphocyte Stimulator. Science, 285, 260-263.

https://doi.org/10.1126/science.285.5425.260

[73] Yu, Q. (2007) Gene Expression Profiling and Proteome Analysis of Decidua in Early Stage of Abortion. Chongqing Medical University.

[74] Fei, N. (2016) Role of miR-122 in Swainsonine-Induced Apoptosis of Goat Placental Trophoblast Cells. Northwest Agriculture and Forestry University.

[75] Sun, J., Zhu, M., Wang, S., Xie, Y., Yu, S., Zhu, X. and Shi, X. (2006) Experimental 
Study on Apoptosis of SGC-7901 Cells Induced by Swainsonine. Chinese Journal of New Drugs, 197-201.

[76] Sun, J.Y., Zhu, M.Z., Wang, S.W., Miao, S., Xie, Y.H. and Wang, J.B. (2007) Inhibition of the Growth of Human Gastric Carcinoma in Vivo and in Vitro by Swainsonine. Phytomedicine, 14, 353-359. https://doi.org/10.1016/j.phymed.2006.08.003

[77] Lu, H., Ma, F., Zhang, L., Wang, J., Wu, C. and Zhao, B. (2015) Swainsonine-Induced Apoptosis Pathway in Cerebral Cortical Neurons. Research in Veterinary Science, 102, 34-37. https://doi.org/10.1016/j.rvsc.2015.07.005

[78] Ron, D. and Walter, P. (2007) Signal Integration in the Endoplasmic Reticulum Unfolded Protein Response. Nature Reviews. Molecular Cell Biology, 8, 519-529.

[79] Fernández, A., Ordóñez, R., Reiter, R.J., González-Gallego, J. and Mauriz, J.L. (2015) Melatonin and Endoplasmic Reticulum Stress: Relation to Autophagy and Apoptosis. Journal of Pineal Research, 59, 292-307. https://doi.org/10.1111/jpi.12264

[80] Sprenkle, N.T., Sims, S.G., Sanchez, C.L. and Meares, G.P. (2017) Endoplasmic Reticu-Lum Stress and Inflammation in the Central Nervous System. Molecular Neurodegeneration, 12, 42-60.

[81] Xu, W., Jin, C., Wang, X., Chen, C. and Cui, L. (2017) Role of Endoplasmic Reticulum Stress Signaling Pathway in Palmitic Acid-Induced Apoptosis of Vascular Endothelial Cells. Chinese Pharmacological Bulletin, 33, 1668-1672.

[82] Lei, L. (2016) Signaling Mechanism of NEFAs Inducing Insulin Resistance in Dairy Cattle through Endoplasmic Reticulum Stress. Jilin University.

[83] Maly, D.J. and Papa, F.R. (2014) Druggable Sensors of the Unfolded Protein Response. Nature Chemical Biology, 10, 892-901. https://doi.org/10.1038/nchembio.1664

[84] Ute, W. and Claudio, H. (2011) Modulating Stress Responses by the UPRosome: A Matter of Life and Death. Trends in Biochemical Sciences, 36, 329-337. https://doi.org/10.1016/j.tibs.2011.03.001

[85] Wang, M. and Kaufman, R.J. (2016) Protein Misfolding in the Endoplasmic Reticulum as a Conduit to Human Disease. Nature, 529, 326-335. https://doi.org/10.1038/nature17041

[86] Gorman, A.M., Healy, S.J.M., Jäger, R. and Samali, A. (2012) Stress Management at the ER: Regulators of ER Stress-Induced Apoptosis. Pharmacology \& Therapeutics, 134, 306-316. https://doi.org/10.1016/j.pharmthera.2012.02.003

[87] Lin, P., Jin, Y., Lan, X., Yang, Y., Chen, F., Wang, N., Li, X., Sun, Y. and Wang, A. (2014) GRP78 Expression and Regulation in the Mouse Uterus during Embryo Implantation. Journal of Molecular Histology, 45, 259-268. https://doi.org/10.1007/s10735-013-9552-1

[88] Yang, Y., Pei, X., Jin, Y., Wang, Y. and Zhang, C. (2016) The Roles of Endoplasmic Reticulum Stress Response in Female Mammalian Reproduction. Cell and Tissue Research, 363, 589-597. https://doi.org/10.1007/s00441-015-2212-x

[89] Jung, E.M., An, B.S., Choi, K.C. and Jeung, E.B. (2012) Apoptosis- and Endoplasmic Reticulum Stress-Related Genes Were Regulated by Estrogen and Progesterone in the Uteri of Calbindin-D(9k) and -D(28k) Knockout Mice. Journal of Cellular Biochemistry, 113, 194-203.

[90] Schroder, S., Matthes, F., Hyden, P., Andersson, C., Fogh, J., Muller-Loennies, S., Braulke, T., Gieselmann, V. and Matzner, U. (2010) Site-Specific Analysis of N-Linked Oligosaccharides of Recombinant Lysosomal Arylsulfatase a Produced in 
Different Cell Lines. Glycobiology, 20, 248-259.

https://doi.org/10.1093/glycob/cwp171

[91] Coralie, B., Yoann, C., Elina, K., Marie-Christine, S., Anne-Marie, M., Frédéric, K., René, C., Pirkko, H., Willy, M., Jean-Claude, M., François, F. and Sandrine, D. (2010) Overexpression of Man2C1 Leads to Protein Underglycosylation and Upregulation of Endoplasmic Reticulum-Associated Degradation Pathway. Glycobiology, 21, 363-375.

[92] Fang, F., Zhang, L., Wang, Q., Li, Y. and Shen, Z. (2007) Down-Regulation of N-Acetylglucosaminyltransferase V Can Induce ER Stress in Human Hepatoma SMMC-7721 Cells through GLUT1 Glycosylation and Activity Decline. Fudan Journal (Medical Edition), 647-651.

[93] Zhang, L., Jin, J., Wang, W., Zhang, A. and Shen, G. (2017) Advances in Research on Anti-Tumor Effects of Swainsonine, an Active Ingredient of Drosophila horticum. Chinese National Folk Medicine, 26, 25-27.

[94] Xu, P., Wang, Y.L., Zhu, S.J., Luo, S.Y., Piao, Y.S. and Zhuang, L.Z. (2000) Expression of Matrix Metalloproteinase-2, -9, and -14, Tissue Inhibitors of Metalloproteinase-1, and Matrix Proteins in Human Placenta during the First Trimester. Biology of Reproduction, 62, 988-994. https://doi.org/10.1095/biolreprod62.4.988

[95] Zhang, J. (2013) Effect of Oxytropis similis Alkaloids on Immune Function and $\alpha$-Mannosidase Gene Expression in Mice. Inner Mongolia Agricultural University.

[96] Mori, M., Kitazume, M., Ose, R., Kurokawa, J., Koga, K., Osuga, Y., Arai, S. and Miyazaki, T. (2011) Death Effector Domain-Containing Protein (DEDD) Is Required for Uterine Decidualization during Early Pregnancy in Mice. Journal of Clinical Investigation, 121, 318-327. https://doi.org/10.1172/JCI44723 